\title{
Evaluation of future hydrological cycle under climate change scenarios in a mesoscale Alpine watershed of Italy
}

\author{
B. Groppelli, A. Soncini, D. Bocchiola, and R. Rosso \\ Dept. of Hydrologic, Roads, Environmental and Surveying Engineering, Politecnico di Milano, 20133 Milano, Italy
}

Received: 8 July 2010 - Revised: 4 December 2010 - Accepted: 15 April 2011 - Published: 21 June 2011

\begin{abstract}
We investigate future (2045-2054) hydrological cycle of the snow fed Oglio $\left(\approx 1800 \mathrm{~km}^{2}\right)$ Alpine watershed in Northern Italy. A Stochastic Space Random Cascade (SSRC) approach is used to downscale future precipitation from three general circulation models, GCMs (PCM, CCSM3, and HadCM3) available within the IPCC's data base and chosen for this purpose based upon previous studies. We then downscale temperature output from the GCMs to obtain temperature fields for the area. We also consider a projected scenario based upon trends locally observed in former studies, LOC scenario. Then, we feed the downscaled fields to a minimal hydrological model to build future hydrological scenarios. We provide projected flow duration curves and selected flow descriptors, giving indication of expected modified (against control run for 1990-1999) regime of low flows and droughts and flood hazard, and thus evaluate modified peak floods regime through indexed flood. We then assess the degree of uncertainty, or spread, of the projected water resources scenarios by feeding the hydrological model with ensembles projections consistent with our deterministic (GCMs + LOC) scenarios, and we evaluate the significance of the projected flow variables against those observed in the control run. The climate scenarios from the adopted GCMs differ greatly from one another with respect to projected precipitation amount and temperature regimes, and so do the projected hydrological scenarios. A relatively good agreement is found upon prospective shrinkage and shorter duration of the seasonal snow cover due to increased temperature patterns, and upon prospective increase of hydrological losses, i.e. evapotranspiration, for the same reason. However, precipitation patterns are less consistent, because HadCM3 and PCM models project noticeably increased precipitation for 2045-2054, whereas CCSM3 provides decreased precip-
\end{abstract}

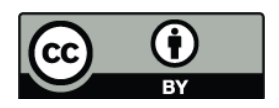

Correspondence to: D. Bocchiola (daniele.bocchiola@polimi.it) itation patterns therein. The LOC scenario instead displays unchanged precipitation. The ensemble simulations indicate that several projected flow variables under the considered scenarios are significantly different from their control run counterparts, and also that snow cover seems to significantly decrease in duration and depth. The proposed hydrological scenarios eventually provide a what-if analysis, giving a broad view of the possible expected impacts of climate change within the Italian Alps, necessary to trigger the discussion about future adaptation strategies.

\section{Introduction}

Global warming is tremendously impacting the climate of mountain areas in temperate regions and the water resource distribution therein (see e.g. Barnett et al., 2005; Solomon et al., 2007; Bates et al., 2008). Hydrologists are therefore required to make accurate predictions of the impacts of climate change on the intensity, amount, and variability of precipitation and temperatures and their fallout upon streamflow regime (Kang and Ramírez, 2007), including the impact of modified seasonal snow cover upon the Alpine environment (Barnett et al., 2005). Snow cover extent, duration and dynamics influence freshwater availability during spring and summer and regulates hydrological cycle of Alpine basins (e.g. Coughlan and Running, 1997; Beniston et al., 2003) and future snow cover dynamics is of tremendous interest thenceforth.

Expected hydrological changes within Alpine catchments include decreased average in channel discharge, as well as modified incidence of extreme events, either low flows (hydrological droughts) or flood flows (e.g. Bavay and Lehning, 2009; Feyen and Dunkers, 2009).

To project the hydrological impact of climate change within Alpine areas, hydrological models are fed with outputs from climatic models (e.g. Drogue et al., 2004;

Published by Copernicus Publications on behalf of the European Geosciences Union. 
Gangopadhyay and Clark, 2005; Kang and Ramirez, 2007) to provide the climatic input for medium to long term impact analysis on water resources (see e.g. Bultot et al., 1992; Beniston, 2003; Hagg and Braun, 2005; Hagg et al., 2007) and on hydrological extremes (see e.g. Burlando and Rosso, 2002b; Boroneant et al., 2006). General Circulation Models (hereon, GCMs) and Limited Area Models (hereon, LAMs) are physically based tools presently used in predicting climate change effects (see e.g. Bardossy, 1997; Bates et al., 1998).

GCMs deliver meteorological variables in a fine time resolution ( $30 \mathrm{~min}$ to a few hours) but in a usually very coarse spatial grid $(250-500 \mathrm{~km})$, while in LAMs a finer computational grid over a limited domain is nested within the coarse grid of a GCM. Although GCMs and LAMs perform reasonably well in simulating synoptic atmospheric fields, they usually poorly reproduce the statistics of historical records at the spatial scales of interest in impact analyses (see e.g. Gangopadhyay and Clark, 2005), and a proper tailoring is therefore required for local use before any accurate guess about hydrologic cycle can be ventured (see e.g. Lammering and Dwyer, 2000; Burlando and Rosso, 1991, 2002a).

Downscaling of GCM-based precipitation data is a key aspect in climatologically- driven hydrological simulation, because the description of hydrological fluxes at the daily scale requires precipitation downscaling at fine resolution (see e.g. Lammering and Dwyer, 2000; Ranzi et al., 1999; Corbari et al., 2009) and the controlling effect of topography can be taken into account (Bavay et al., 2009).

A class of methods that is often adopted is statistical downscaling via Stochastic Space Random Cascade approach, henceforth termed SSRC (Tessier et al., 1993; Over and Gupta, 1994, 1996; Menabde and Sivapalan, 2000; Veneziano and Langousis, 2005; Veneziano et al., 2006), already used for downscaling of precipitation from GCMs for climate change projections (Kang and Ramírez, 2007) as well as for improvement of water balance estimation (see e.g. Lammering and Dwyer, 2000).

In this paper we develop projections of future hydrological regime within the mesoscale $\left(\approx 1800 \mathrm{~km}^{2}\right)$ Oglio river basin in the Retiche Italian Alps.

This study is carried out under the umbrella of the CARIPANDA project, funded by the Cariplo Foundation of Italy, and aiming to evaluate scenarios for water resources in the Adamello Natural Park of Italy, laid within the Oglio river watershed, in a window of $50 \mathrm{yr}$ or so. The Park also includes the Adamello Group, made of several glacierized areas (ca. $10 \mathrm{~km}^{2}$ contributing to the Oglio watershed), nesting the widest Italian Glacier, named Adamello, spreading over an area of about $18 \mathrm{~km}^{2}$ (see e.g. Maragno et al., 2009; Bocchiola and Diolaiuti, 2010; Ranzi et al., 2010).

We use an already developed (Groppelli et al., 2010) and well assessed SSRC downscaling approach $\left(2 \times 2 \mathrm{~km}^{2}\right)$ to downscale the climate projections (storyline A2) from three GCMs made available by the IPCC panel (HadCM3, PCM,
CCSM3) chosen on the basis of previous studies (Groppelli and Pengo, 2005). We focus on the decade 2045-2054, to provide hydrological scenarios for a period centred around year 2050, as required by the CARIPANDA project. For reference, we also produce a climate scenario based upon the locally observed trends of temperature and precipitation we highlighted in a previous study (Bocchiola and Diolaiuti, 2010).

This locally data driven scenario, called LOC, is used as a benchmark for those provided by the chosen GCM models, carrying information about global climate.

We then set up a minimal, altitude belts based model, which uses input of precipitation and temperature to drive the hydrological cycle of the watershed, including snowcover dynamics, hydrological losses through evapotranspiration, groundwater storage and flow, overland flow, and simplified flow routing. The lack of comprehensive information concerning other main hydrologically meaningful variables (e.g. solar radiation, wind speed, air moisture) makes use of more complex models infeasible. The proposed model is preliminarily tuned to properly mimic hydrological cycle of the Oglio watershed for the control period CO, 1990-1999, and then used for the purpose of hydrological projections.

The precipitation and temperature fields from the four available climate scenarios (three GCMs plus LOC) are then used to feed a minimal hydrological model, to develop corresponding hydrological scenarios. We then discuss the modified hydrological cycle as obtained from the proposed scenarios, including modified seasonality of snow cover, low flows amount, and duration and floods, as portrayed using standard flow descriptors highlighted within the available literature (e.g. Clausen and Biggs, 2000; Smakhtin, 2001).

We draw some preliminary conclusions concerning the expected impact of climate change upon water availability in Italian Alpine watersheds, and we briefly comment about the possible adaptation strategies therein.

\section{Case study area}

\subsection{Oglio watershed}

The study area (Fig. 1) covers the mountainous part of the Lombardia region in the central Alpine and Pre-Alpine area. This includes the upper Oglio snow fed watershed, of about $1800 \mathrm{~km}^{2}$ in area. The Oglio river basin is the major tributary to Lake Iseo and its emissary, the lower Oglio, is a left-hand tributary of the Po river. Elevation ranges from $185 \mathrm{~m}$ a.s.l. at Sarnico to $3.538 \mathrm{~m}$ a.s.l. of the Adamello peak. The Oglio river valley displays alpine climate, with very cold winter and moderate summer temperatures, considerable solar radiation, and high frequency of clear sky conditions, especially during winter. Average annual precipitation in the Park area is about $1300 \mathrm{~mm}^{-1}$. Snowfall is frequent from October to May, and the snow cover generally persists until July 
at the highest altitudes. The precipitation regime according to the Köppen-Geiger climate classification (e.g. Peel et al., 2007) belongs to the temperate/cool continental class, featuring seasonal continuous snow cover above $1000 \mathrm{~m}$ a.s.l. or so (e.g. Bocchiola and Rosso, 2007; Bocchiola, 2010; Bocchiola and Groppelli, 2010), with a maximum of precipitation during the end of the summer and fall and a minimum during the winter. Runoff is mainly influenced therein by snow melt in Spring and by rainfall in early fall. Several recent studies indicate consistent evidence of climate warming within this area and the Northern Italian Alps, therein effecting available snow covered area and snow water equivalent (hereon, SWE) at thaw, and leading to glaciers' downwasting (e.g. Citterio et al., 2007; Maragno et al., 2009; Bocchiola and Diolaiuti, 2010 ) and in turn a modified hydrological cycle (e.g. Barontini et al., 2009).

\section{Data base}

\subsection{Historical data base}

We use here a historical data base of meteorological variables (daily temperature and precipitation) obtained by merging different data bases from the Regional Environmental Protection Authority (ARPA) of Lombardia Region, the Consorzio dell'Oglio Authority, the annals of the Italian Hydrographic Service (SIMN), the regional agricultural development authority (ERSAL), and the ENEL hydropower company of Italy, which participated within the CARIPANDA project as a stakeholder. We used data from 20 most complete rain gages and 20 most complete thermometers within the Oglio watershed (Fig. 1). The main features of the measuring stations are reported in Table 1. In this watershed, there are no stations of either wind speed, solar radiation, or moisture that we know of with a considerable data base, so we could not use these variables in building our hydrological model. The outflows of Oglio river from Lake Iseo are regulated by a dam placed at the lake outlet in Sarnico (Fig. 1), built during 1931-1933. Pool level of the lake vary slightly with respect to reference level of $185.15 \mathrm{~m}$ a.s.l. Pool level operation is carried out daily by the Oglio river regulation authority (Consorzio dell'Oglio), in order to satisfy downstream irrigation demand, and to provide flood regulation. During the building of the Sarnico dam the modified flow discharge due to flow regulation was assessed, and a stage-discharge relationship was then developed that provides the (estimated) natural outlet discharges from the lake (Consorzio dell'Oglio, 2009). The historical series of these data began in 1933 and was made available by the Consorzio dell'Oglio authority. This series is used here to calibrate the hydrological model, which we subsequently use for projection of future hydrological regime. The average daily flow discharge estimated for the period 1933-2007 is $Q_{\mathrm{av}}=56.8 \mathrm{~m}^{3} \mathrm{~s}^{-1}$. For the control period 1990-1999 we found $Q_{\mathrm{av}}=53.9 \mathrm{~m}^{3} \mathrm{~s}^{-1}$.
Further data used for hydrological purposes are the DTM of the Oglio river, provided by the Lombardia Region ( $20 \mathrm{~m}$ cell size), and geological and land use maps taken from CORINE Land cover deemed necessary to provide estimation of the maximum soil storage potential $S_{I I}$, according to the SCS-CN method.

\subsection{Scenario GCMs data, IPCC A2}

The Special Report on Emission Scenarios - SRES by the Intergovernmental Panel on Climate Change (Nakicenovic and Swart, 2000) - described four possible future storylines (A1, A2, B1, B2). Each one describes the effect of different potential causes of greenhouse gas (GHG) emissions and their possible future dynamics. Four different scenarios were defined based on the storylines, considering possible demographic, social, and economical evolution trends and technological developments as causes for future GHG emissions. Each SRES scenario family assumes one out of the four possible storylines and "do not include additional climate initiatives, which means that no scenarios are included that explicitly assume implementation of the United Nations Framework Convention on Climate Change or emission targets defined by the Kyoto Protocol" (Houghton et al., IPCC 2001), which entered into force only upon 16 February 2005 . We choose to use temperature and precipitation data generated via the IPCC SRES A2 Scenario, covering the $50 \mathrm{yr}$ period 20102060, so described by Beniston (2004): “A2 scenarios assume little change in economic behaviour. In addition, rising population levels and relatively little international collaboration on resource and environmental protection exacerbate the problem of emissions; the A2 are sometimes referred to as "Business-as-usual", a phrase that was coined for one of the previous sets of IPCC scenarios".

We considered the time window 2045-2054 to analyze future climate and environmental conditions centred around 2050 , i.e. to test effects of potential climate change at the middle of the present century, consistently with the purposes of the CARIPANDA project.

\subsection{GCMs and local scenario}

Within GCM models the earth-atmosphere system is discretized using a homogenous structure of three-dimensional cells, with different size in the horizontal and vertical direction. The size of these volumes of integration (boxes) changes from model to model. Several processes occurring at a resolution smaller than that of the grid's (subgrid processes) cannot be represented explicitly.

Typically, GCMs provide a bad representation of the subgrid processes leading to precipitation, especially when topographically controlled, because its characteristic scales are smaller than grid size. Therefore, downscaling is necessary. Still, GCMs carry considerable information concerning large scale forcings to local climate, so their use is appropriate for 


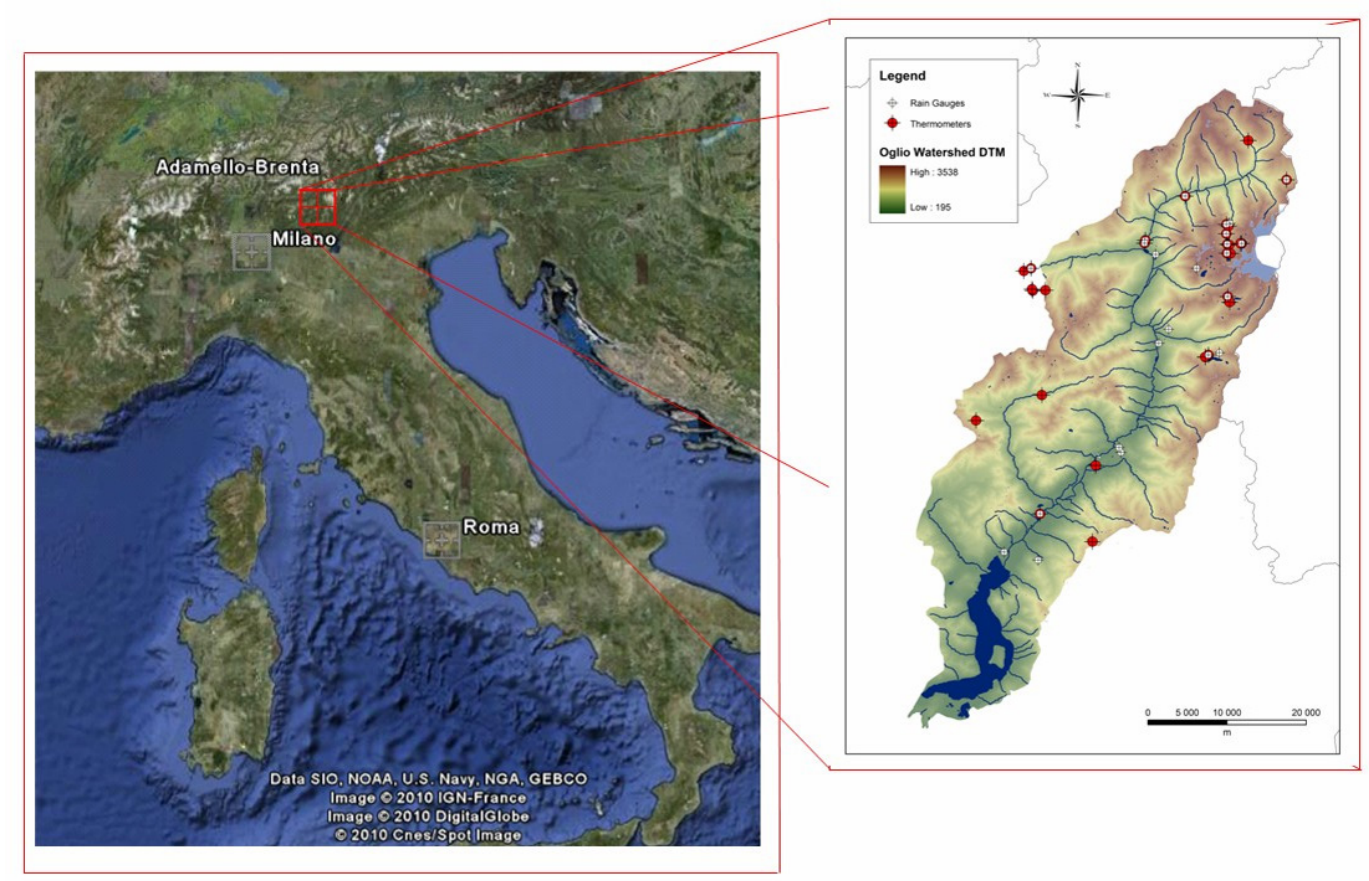

Fig. 1. The study area: Oglio river basin in the Italian Alps. Red dots are rain gage network. Blue dots are available thermometers.

projections of climate change impact. For the present study we use the output from three GCMs.

Namely, we use the Parallel Climate Model (PCM) and Community Climate System Model (CCSM3) produced from the National Center for Atmospheric Research di Boulder, in Colorado, together with the Hadley Centre Coupled Model (HadCM3), produced from the Hadley Centre for Climate Prediction and Research.

We chose the HadCM3 model because within the international literature it is proposed as a reference one (e.g. Faggian and Giorgi, 2009), while the PCM model was demonstrated to be accurate enough in terms of estimated precipitation upon the area of the Po river, where the Oglio river is laid (e.g. Groppelli et al., 2010). On the other hand, model CCSM3 represents possibly one of the most recent evolutions of the available climatic models, as confirmed by the remarkably reduced three-dimensional grid.

This model is therefore examined here to evaluate the changes in projected hydrology when a GCM with considerable resolution is adopted. We used the latest releases of the GCMs outputs made available from the IPCC that we know of.

In Table 2 the main features of the three chosen models are given. The column "grid size" specifies the size of the cells expressed in degrees of longitude and latitude, while in the next column the number of columns and lines that compose the full calculation grid is reported. The number of layers indicates how many levels are used for discretization of the atmosphere in the vertical direction. As previously mentioned, the CCSM3 is the one with the finer resolution, both in horizontal and in vertical direction. In Fig. 2, the grids of the three models used on the interested area of Italy North are shown.

To compare the outputs of the GCMs, which provide information about the global scale climate trends, against historical trends actually observed at the local scale (1990-1999), we developed a climate projection based upon the findings from a recent study carried out within the Oglio catchment area (Bocchiola and Diolaiuti, 2010). Particularly, we applied a trend of daily temperature as observed within that study, where the yearly averaged least daily temperature, $T_{\min \text {,av }}$ was observed to increase with a significantly positive rate (substantially constant with altitude and of about $+0.043^{\circ} \mathrm{Cy}^{-1}$ on average). In that study we did not find any significant change of precipitation, therefore yearly precipitation has been maintained constant. This scenario is called LOC.

\section{Methods}

\subsection{Downscaling approach}

We produced precipitation scenarios using a downscaling method based upon the theory of stochastic space random cascade, SSRC (Groppelli et al., 2010). The SSRC is tuned using ten years of daily precipitation data (1990-1999) upon the Oglio catchment. Calibration of the model is carried out using the approach of Scale Recursive Estimation 


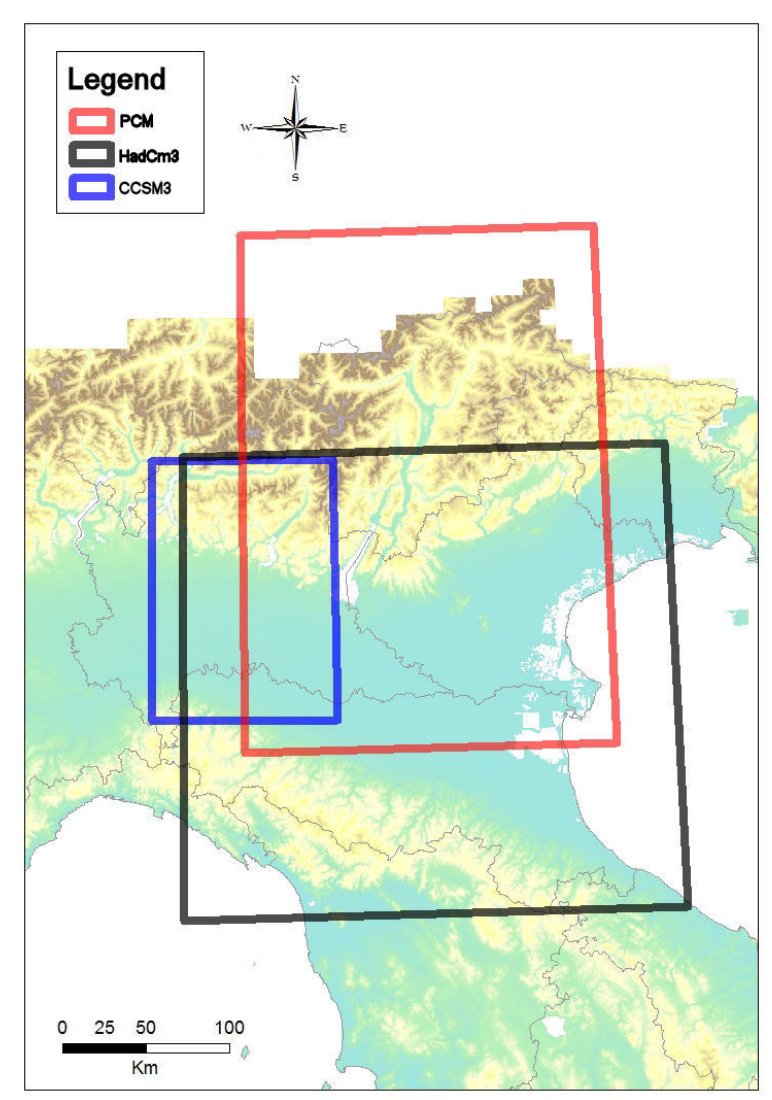

Fig. 2. Grids of the chosen GCM models upon the Oglio watershed.

(SRE) coupled with maximum likelihood estimation, by the Expectation Maximization algorithm, EM (see e.g. Gupta et al., 2006).

The downscaling approach using SSRC entails two main steps, namely (i) correction of daily bias $\mathrm{Bias}_{\mathrm{GAO}}$, and (ii) spatial disaggregation of precipitation.

The first step is specific for each GCM and it is necessary to make average daily precipitation upon the catchment (as provided by the GCM itself) consistent with those observed in the area. First, we calculated the area averaged precipitation upon the catchment $R_{\mathrm{GAO}}$ for the control period. Then, we corrected the area average rainfall $R_{\mathrm{GCM}}$ from the GCM by a random multiplicative process, Bias $_{\mathrm{GAO}}$ explicitly considering intermittence (i.e. dry spells):

$$
\begin{aligned}
& \operatorname{Bias}_{\mathrm{GAO}}=\mathrm{R}_{\mathrm{GAO}} / \mathrm{R}_{\mathrm{GCM}}=\mathrm{B}_{\mathrm{GAO}} \mathrm{B}_{0} \mathrm{~W}_{0} \\
& P\left(B_{0}=0\right)=1-p_{0} \\
& P\left(B_{0}=p_{0}^{-1}\right)=p_{0} \\
& E\left[B_{0}\right]=p_{0}^{-1} p_{0}+0\left(1-p_{0}\right)=1 \\
& W_{0}=e^{\left(w_{0}-\sigma_{w 0}^{2} / 2\right)} \\
& E\left[W_{0}\right]=1
\end{aligned}
$$

Table 1. Measuring stations and measured variables during 19901999. $C$ is completeness index (i.e. number of available daily measurements out of the total number of days in the measuring period).

\begin{tabular}{llll}
\hline Station & Altitude [m a.s.l.] & Variable & $C[]$. \\
\hline Aprica & 1181 & Temp, Rain & $0.16,1$ \\
Aprica Magnolta & 1950 & Temp & 0.69 \\
Aprica Paese & 1175 & Temp & 0.46 \\
Bessimo & 215 & Temp, Rain & $0.49,0.80$ \\
Bienno & 500 & Rain & 0.8 \\
Borno Trobiolo & 400 & Rain & 0.7 \\
Cedegolo & 400 & Rain & 1 \\
Cevo Co & 1061 & Rain & 0.9 \\
Colere Monte Polzone & 1570 & Temp & 0.29 \\
Costa Volpino & 248 & Rain & 0.7 \\
Diga Di Venerocolo & 2520 & Temp, Rain & $0.35,1$ \\
Edolo & 699 & Temp & $0.63,0.70$ \\
Edolo & 690 & Temp, Rain & $0.64,1$ \\
Esine & 700 & Temp & 0.24 \\
Fraine & 850 & Rain & 0.7 \\
Laghetto D'Avio Diga & 1868 & Rain & 1 \\
Lago Baitone & 2258 & Rain & 1 \\
Lago Benedetto & 1905 & Rain & 1 \\
Lago D'arno & 1820 & Temp, Rain & $0.61,1$ \\
Lago D'arno & 1830 & Temp & 0.31 \\
Lago D'avio & 1902 & Temp, Rain & $0.69,1$ \\
Lago Salarno & 2038 & Temp, Rain & $0.52,1$ \\
Montecampione & 1765 & Temp & 0.35 \\
Pantano D'avio & 2105 & Temp & 0.34 \\
Pantano D'avio & 2325 & Temp, Rain & $0.61,1$ \\
Passo Del Tonale & 2100 & Rain & 0.5 \\
Passo Tonale & 1777 & Temp & 0.5 \\
Ponte Di Legno & 1600 & Temp & 0.31 \\
Schilpario & 1150 & Temp & 0.02 \\
Sonico & 1777 & Rain & 1 \\
Vezza D'oglio & 1070 & Temp & 0.5 \\
Vezza D'oglio & 1090 & Rain & 0.7 \\
\hline & & & \\
\hline
\end{tabular}

where $B_{\mathrm{GAO}}, p_{0}$, and $\sigma_{w 0}^{2}$ are the model parameters to be estimated from data. $B_{\mathrm{GAO}}$ is a constant term, forcing the average daily value of $R_{\mathrm{GAO}}$ to equate its sample value, because of the GCM underestimation of precipitation during wet spells. The term $B_{0}$ is a $\beta$ model generator (see Over and Gupta, 1994). It gives the probability that the rain rate $R_{\mathrm{GAO}}$ for a given day is non zero, conditioned upon $R_{\mathrm{GCM}}$ being positive, and it is modelled here by a binomial distribution. The term $W_{0}$ is a "strictly positive" generator. It is used to add a proper amount of variability to precipitation during spells labelled as wet. Model estimation of Bias ${ }_{\mathrm{GAO}}$ is extensively explained elsewhere (Groppelli et al., 2010) and the reader is addressed therein. The spatial downscaling approach (e.g. Bocchiola, 2007) is instead specific for the catchment and does not depend upon GCM, because it depicts the spatial variability of precipitation within the catchment area.

Spatial rainfall distribution is modelled as a branching tree structure (see e.g. Bocchiola, 2007). Each layer in the tree represents a lattice, where the size of the cells (or nodes) is coincident with the resolution (or scale) associated to the 
Table 2. Description of GCM models.

\begin{tabular}{|c|c|c|c|c|c|}
\hline Model & Research Centre & Nation & Grid size $\left[{ }^{\circ}\right]$ & $\mathrm{n}^{\circ}$ cells $[]$. & $\mathrm{n}^{\circ}$ layers $[]$. \\
\hline HadCM3 & Hadley Center for Climate Prediction and Research & U.K. & $2.5^{\circ} \times 3.75^{\circ}$ & $96 \times 73$ & 19 \\
\hline PCM & National Center for Atmospheric Research & USA & $2.8^{\circ} \times 2.8^{\circ}$ & $128 \times 64$ & 18 \\
\hline CCSM3 & National Center for Atmospheric Research & USA & $1.4^{\circ} \times 1.4^{\circ}$ & $256 \times 128$ & 26 \\
\hline
\end{tabular}

samples of the rainfall field obtained with some measurement device(s), or otherwise estimated. The node at the coarsest resolution is called "root" node, while the nodes at the finest resolution are called "leaves". Named $R_{0}$, the average rainfall rate at the synoptic scale, the dimensionless rainfall rate in any cell, indexed by $i$, at a generic scale, $s$, namely $X_{s}^{i}=R_{s}^{i} / R_{0}$ is

$X_{s}^{i}=X_{0} \prod_{j=1}^{s} Y_{j}^{i}$.

Weights $Y_{s}$ (Over e Gupta, 1996) are described as follows:

$$
E\left[Y_{s}^{i}\right]=1 ; \operatorname{Var}\left[Y_{s}^{i}\right]=\sigma_{Y s}^{2}
$$

Rainfall processes display spatial intermittence, this meaning that the process has a finite probability mass at zero. Based upon Over and Gupta (1996), we modelled the cascade generator here as the product of two independent generators, as

$Y_{s}^{i}=B_{s}^{i} W_{s}^{i}$

where $W_{S}$ is a "strictly positive" generator, modelling the rainfall process for the rainy areas, and $B_{S}$ is a $\beta$ model generator, i.e. the probability that rain rate in a cell at scale $s$ is non null, conditioned on its parent being positive, defined as in Eq. (1) above. The details of SSRC are also reported elsewhere (Bocchiola, 2007; Groppelli et al., 2010) and are not reported here. We investigated scaling of the seasonal cumulated precipitation against altitude for all the investigated rain gauges here (reported in Groppelli et al., 2010), but we found no significant dependence against altitude in any season. Therefore, precipitation is held constant with respect to altitude (see e.g. Badas et al., 2006 for an approach to modelling of spatially varying precipitation within random cascades). We convert total precipitation into snow by use of a ground temperature $T$. To do so, we need an estimated temperature at each altitude (i.e. belt) of our watershed. We use the GCMs daily temperature $T_{\mathrm{GCM}}$, in back cast mode against the observed temperatures in our stations (Fig. 1), to evaluate a reference altitude $A_{\mathrm{GCM}}$. This is the altitude where the temperature $T_{\mathrm{GCM}}$ is observed, i.e. the average altitude level at which the GCM temperature data are representative. For each month $i$ of the year, we evaluated the mean (i.e. upon the period 1990-1999) temperature lapse rate
$r_{T, i}$ against altitude. Then we calculated the mean (19901999) monthly temperature $T_{\mathrm{GCM}, i}$ and we evaluated $A_{\mathrm{GCM}, i}$ at which $T_{\mathrm{GCM}, i}$ is representative.

$T_{\mathrm{GCM}, i}=T_{0, i}-A_{\mathrm{GCM}, i} r_{T, i}$,

with $T_{0, i}$, altitude at zero $\mathrm{m}$ asl, and $r_{T, i}$ lapse rate $\left({ }^{\circ} \mathrm{C} \mathrm{km}{ }^{-1}\right.$ in absolute value), as estimated from data. In the reasonable hypothesis that $T_{\mathrm{GCM}, i}$ remains unchanged in the future, we use its value as a reference for future projections. We then calculate the temperature at different altitudes (i.e. belts) in the whole watershed for a given date $d$ in month $i$ in a given altitude belt $j$ by use of daily GCM temperature $T_{\mathrm{GCM}, d}$ and of lapse rate $r_{T, i}$, as

$T_{j, d}=T_{\mathrm{GCM}, d}-\left(A_{j}-A_{\mathrm{GCM}, i}\right) r_{T, i}$.

During ablation season (i.e. after 15 April on average) we use a degree day model, with melt factor evaluated in previous studies (Bocchiola et al., 2010). Good suitedness of the method to represent seasonal snow cover was tested using SWE data from snow stations within the area with good results (Groppelli et al., 2010).

For the hydrological model set up here, which uses a semidistributed approach with altitude belts, the outputs from the SSRC model, together with temperature and snowfall, are averaged upon the altitude belts.

\section{Hydrological model}

\subsection{Introduction}

We introduce and set up here a model able to describe the hydrological dynamics of the Oglio river. We use a semidistributed altitude belts-based model, able to mimic deposition and ablation of snow cover, evapotranspiration losses, recharge of the groundwater reservoir, and formation of in channel discharge. We preliminarily included within the model the amount of water coming from glacial ablation from the Adamello Group's glaciers (approximately $10 \mathrm{~km}^{2}$ contributing to the Oglio catchments). However, this contribution is modest (less than $1 \%$ in average, with summer peaks around 3-4\%). Therefore, this contribution will not be considered henceforth.

We used here a simplified version of the Distributed Hydrological Model, DHM (Wigmosta et al., 1994; Chen et al., 
2005). This entails the fundamental components of the hydrological budget. Two mechanisms of flow formation are considered: superficial and groundwater (lumping here rooting zone and subsurface flows, see Wigmosta et al., 1994). The model is based on mass conservation equation, and considers in particular the variation of the water content within the ground $[\mathrm{mm}]$ in two consecutive time steps $(t, t+\Delta t)$, as

$S^{t+\Delta t}=S^{t}+R+M_{s}+M_{i}-\mathrm{ET}-Q_{g}$,

where $S$ is the water content of the ground, $R$ the liquid rain, $M_{s}$ snowmelt, $M_{i}$ the glacial ablation (not considered here as explained), ET the actual evapotranspiration, and $Q_{g}$ the groundwater discharge. Snowmelt $M_{s}$ is estimated according to a degree day method

$M_{s}=D_{D}\left(T-T_{t}\right)$,

with $T$ daily mean temperature, $D_{D}$ melt factor, $D_{D}=2.31 \mathrm{~mm}^{\circ} \mathrm{C}^{-1} \mathrm{~d}^{-1}$, and $T_{t}$ threshold temperature, $T_{t}=0^{\circ} \mathrm{C}$ (Bocchiola et al., 2010). The overland flow $Q_{s}$ occurs for saturated soil

$\begin{array}{ll}Q_{s}=S^{t+\Delta t}-S_{\text {Max }} & \text { if } S^{t+\Delta t}>S_{\text {Max }} \\ Q_{s}=0 & \text { if } S^{t+\Delta t} \leq S_{\text {Max }}\end{array}$

with $S_{\text {Max }}$ greatest potential soil storage [mm]. Potential evapotranspiration is calculated using Hargreaves equation, only requiring temperature data (see e.g. Shuttleworth, 1992)

$\mathrm{ETP}=0.0023 S_{0} \sqrt{D T_{m}}(T+17.8)$,

in $\mathrm{mmd}^{-1}$, where $S_{0}\left[\mathrm{mmd}^{-1}\right]$ is the evaporating power of solar radiation, and $D T_{m}\left[{ }^{\circ} \mathrm{C}\right]$ is the thermometric monthly mean excursion. Once potential evapotranspiration is known, actual evapotranspiration ET can be calculated. ET is made of effective evaporation from the ground $E_{s}$ and of effective transpiration from the vegetation $T_{s}$, both functions of ETP via two coefficients $\alpha$ and $\beta$, depending on the state of soil moisture (water content, $\theta$, given by $S / S_{\operatorname{Max}}$ ) and from the fraction of vegetated soil $\left(f_{v}\right)$ upon the surface of the basin (see e.g. Brutsaert, 2005; Chen et al., 2005)

$E s=\alpha(\theta) \operatorname{ETP}\left(1-f_{v}\right)$

$T s=\beta(\theta) \operatorname{ETP} f_{v}$,

with

$$
\begin{aligned}
& \alpha(\theta)=0.082 \theta+9.173 \theta^{2}-9.815 \theta^{3} \\
& \beta(\theta)=\frac{\theta-\theta_{w}}{\theta_{l}-\theta_{w}} \text { if } \theta>\theta_{w} \\
& \beta(\theta)=0 \quad \text { if } \theta \leq \theta_{w}
\end{aligned}
$$

where $\theta_{w}$ is wilting point water content, while $\theta_{l}$ is water content at field capacity. Actual evapotranspiration is then

$\mathrm{ET}=E s+T s$.

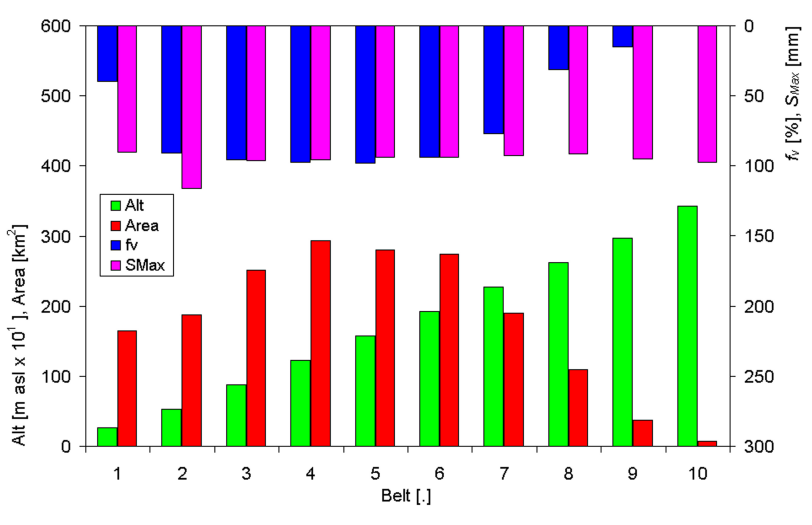

Fig. 3. Main features of the selected altitude belts.

Groundwater discharge is here simply expressed as a function of soil hydraulic conductivity and water content (see e.g. Chen et al., 2005)

$Q_{g}=K\left(\frac{S}{S_{\mathrm{Max}}}\right)^{k}$,

with $K$ saturated permeability and $k$ power exponent. Equations (7-14) are solved using ten elevation belts, with homogenous distribution, inside the basin. The flow discharges from the belts are routed to the outlet section through a semidistributed flow routing algorithm. This algorithm is based upon the conceptual model of the instantaneous unit hydrograph, IUH (e.g. Rosso, 1984). For calculation of the in stream discharge we hypothesize two (parallel) systems (groundwater, overland) of linear reservoirs (in series), each one with a given number of reservoirs $\left(n_{g}\right.$ and $\left.n_{s}\right)$. Each of such reservoirs possesses a time constant (i.e. $k_{g}, k_{s}$ ). We assumed that for every belt the lag time grows proportionally to the altitude jump to the outlet section, until the greatest lag time (i.e. $T_{\text {lag, } g}=n_{g} k_{g}$ for the groundwater system and $T_{\mathrm{lag}, s}=n_{s} k_{s}$ for the overland system). So doing, each belt possesses different lag times (and the farther belts the greater lag times). In Fig. 3 we report altitude belt distribution (mean belt altitude, area) and vegetation cover $f_{v}$.

\subsection{Model calibration}

Since the Oglio catchment is subjected to considerable regulation, a validation study of daily discharges from the model should be undertaken with care. Notice that the model developed here is not aimed to forecast the "natural" discharges within the river, which are not known in practice. The model must in fact be used like a tool to describe the likely dynamics of river flows under "natural" conditions, i.e. in response to present climate conditions, to be used as a benchmark for comparison of future hydrological conditions. Therefore, we carry out calibration of the model in order to allow a reasonably depiction of flow volumes. In Table 3 they are specified 
Table 3. Oglio at Sarnico. Hydrological model parameters. In italics are values calibrated against observed discharges

\begin{tabular}{llll}
\hline Parameter & Description & Value & Method \\
\hline$k_{g}, k_{S}[\mathrm{~d}]$ & Reservoir time constant, ground/overland & $7,3.5$ & Max $R^{2}-Q_{\text {ind }}$ \\
$n_{g}, n_{s}$ & Reservoirs, ground/overland & $3 / 3$ & Literature \\
$K\left[\mathrm{mmd}^{-1}\right]$ & Saturated conductivity & 3.15 & Flow volumes \\
$k[]$. & Groundwater flow exponent & 1 & Literature \\
$f_{v}[]$. & Vegetation fraction, average value & 0.7 & Soil cover \\
$\theta_{w}, \theta_{l}[]$. & Water content, wilting /field capacity & $0.15,0.35$ & Literature \\
$S_{\mathrm{Max}}[\mathrm{mm}]$ & Maximum soil storage, average & 90 & Soil cover/Land use \\
Statistics $_{R^{2}[.]}$ & Description & Value & Method \\
$Q_{\text {av }}\left[\mathrm{m}^{3} \mathrm{~s}^{-1}\right]$ & Nash Sutcliffe & 0.40 & Maximization $\left(k_{s}, k_{g}\right)$ \\
$Q_{\text {ind }}\left[\mathrm{m}^{3} \mathrm{~s}^{-1}\right]$ & Average daily flows observed/simulated & $53.95 / 53.92$ & Calibration $K$ \\
\hline
\end{tabular}

as the parameters that were effectively used for the calibration as well as those that were estimated a priori on the basis of preliminary considerations and of the analysis of the available literature.

Among the model parameters, the value of $S_{\mathrm{Max}}$ is of considerable interest, since it drives the production of overland flow. If one compares this parameter to the parameter $S$ of the method $S C S-C N$, which possesses the analogous meaning of maximum soil storage, it is possible to estimate in the first instance the value of $S_{\text {Max }}$ based upon that method. The analysis of the lithology and land use of the area under investigation allows construct of a map of the $C N_{I I}$ value (and therefore of $S_{I I}$ ) for the river basin. We therefore used this map (not shown for shortness) to provide the $S_{\mathrm{Max}}$ value for the model. The average value is $S_{I I \text {, av }}=96$. Using values of $S_{\mathrm{Max}}$ equal to $S_{I I}$, acceptable results were obtained, as reported further on. In Fig. 3, the average value of $S_{\mathrm{Max}}$ for each belt is reported.

The wilting point $\theta_{w}=0.15$ is chosen based upon available references (Chen et al., 2005; Wang et al., 2009). The field capacity was set to $\theta_{l}=0.35$, using an average value for mixed grounds, according to studies on a wide range of soils (e.g. Ceres et al., 2009). However, a sensitivity analysis to these parameters indicated slight variations of the model results. Normally, the number of reservoirs for the overland flow phase depends on the morphology of the basin, expressed e.g. through morphometric indexes (e.g. Rosso, 1984). However, an analysis of the values observed within several studies indicates an average value of $n_{s}=3$, which we use here. In analogy with this choice, the number of groundwater reservoirs may be reasonably linked to the topography, and we set $n_{g}=3$. A greater variability is instead necessary for the appraisal of the time constants $k_{s}$ and $k_{g}$ that define the lag time of catchments, and are closely linked to its size and to the characteristic flow velocity (e.g. Bocchiola et al., 2004). We estimated the values of $k_{s}$ and $k_{g}$ in order to meet two criteria. The first criterion is the adapta- tion of the simulated discharges against the "observed" ones through maximization of the Nash Sutcliffe $R^{2}$ coefficient. The second criterion concerns the ability of the model to acceptably describe the flood discharges. Although the model is not specifically aimed to describe floods, a very inaccurate description of floods would indicate a limited ability of the model to depict overland flows. Furthermore, the ability of the model to accurately describe overland flow allows a first appraisal of the future floods. We carried out several simulations, where we tried to maximise $R^{2}$ as a function of $k_{s}$ and $k_{g}$. Within the range of possible values giving an acceptable value of $R^{2}$, we chose the value of $k_{s}$ that showed the best adaptation in terms of the average yearly flood peak, or index flood $Q_{\text {ind }}$ (e.g. Bocchiola et al., 2003). This procedure is possible since $k_{s}$ has greater influence during the flood events, while $k_{g}$ mainly effects outflows during low flow periods. In Table 3 we report the results. The maximum value of $R^{2}=0.41$ was obtained taking $k_{s}=3 \mathrm{~h}, k_{g}=7 \mathrm{~h}$. The simulated index flood would be $Q_{\text {ind }, m}=353 \mathrm{~m}^{3} \mathrm{~s}^{-1}$, against an observed value of $Q_{\text {ind }, o}=329 \mathrm{~m}^{3} \mathrm{~s}^{-1}$. Taking $k_{s}=2.5$, one obtains $Q_{\text {ind }, m}$ $=325 \mathrm{~m}^{3} \mathrm{~s}^{-1}$ (and $R^{2}=0.40$ ). Therefore, a fine tuning of $k_{s}$ against $Q_{\text {ind }}$ seems proper, since a small variation of $R^{2}$ is obtained. In Fig. 4 model calibration is reported. Notice that the series of "observed" flows may be effected by flow regulation and some noise may effect the series due to flow reconstruction, as reported in Sect. 3. These are likely the reasons why a relatively low value of $R^{2}=0.40$ is obtained. The saturated permeability value $K=3.15 \mathrm{mmd}^{-1}$ is consistent with the available literature for a wide range of observed soils, where values between $0.1 \mathrm{mmd}^{-1}$ and $10 \mathrm{mmd}^{-1}$ are found (e.g. Timlin et al., 1999; Wang et al., 2009). This parameter has substantial importance during periods of low flows, and in the reasonable hypothesis that the groundflow is linearly varying with the water content ( $k=1$ in Eq. 14), the proposed value of $K$ is the main parameter influencing mean flows. The yearly average discharge simulated from the 


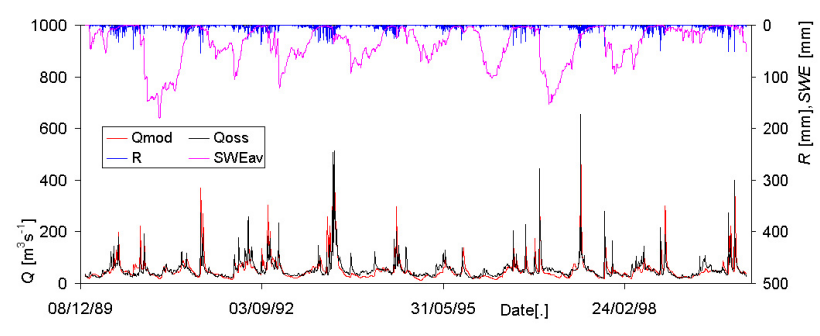

Fig. 4. Oglio at Sarnico. Model calibration. Mean daily discharges during 1990-1999. Average Rainfall and snowpack SWE reported.

model is $Q_{\mathrm{av}, m}=53.92 \mathrm{~m}^{3} \mathrm{~s}^{-1}$ against the observed value of $Q_{\mathrm{av}, o}=52.95 \mathrm{~m}^{3} \mathrm{~s}^{-1}$ (Bias $=-0.06 \%$ ). Notice that the use of $K=3.15$ as reported also results in the highest values of $R^{2}$, according to a sensitivity analysis.

In Fig. 4 the liquid precipitation, $R$, averaged upon the catchment for altitude belts, and the relative values of stored water in snowpack (SWE) are reported. It is clearly visible the dependence of the hydrological regime upon the dynamics of the snowpack melt, feeding river discharges during spring and summer.

\section{Hydrological scenarios}

\subsection{Future hydrological regimes}

In Table 4 the main results of the scenario simulations are reported. In Fig. 5 the simulated discharges from the catchments are reported. In Fig. 6 the seasonal snowpack water, SWE, for two elevation belts, 4 (mean altitude $1225 \mathrm{~m}$ a.s.l.), and 9 (mean altitude 2975 m a.s.l.) is given. In Fig. 7, the actual evapotranspiration ET is shown for the two belts, while Fig. 8 reports soil water content $S$. Figure 9 displays monthly averaged discharges. The LOC scenario displays an average increase of temperature of approximately $2.1^{\circ} \mathrm{C}$ with respect to the control period 1990-1999 (Table 4), with unchanged precipitation.

The first visible is the decrease of the amount and duration of the seasonal snow cover (Table 4) for all altitudes (Fig. 6a). Moreover, the increased potential evapotranspiration ETP, depending upon temperature, leads to increased actual evapotranspiration ET (Table 4, Fig. 7a). This scenario displays the greatest proportional increase of ET (coefficient $\phi_{\mathrm{ET}}=\mathrm{ET} / P_{\mathrm{CUM}}$ in Table 4$)$ showing decreased discharges (Table 4, Fig. 5), in particular in late spring (Fig. 9). Contrarily, late summer and fall flows seem increased. This effect was seen in various international studies upon snowfed catchments (e.g. Barnett et al., 2005; Beniston et al., 2007; Bavay et al., 2009), and it is due to decreased snow accumulation at the highest altitudes during late summer and early fall (Fig. 6a).

The A2 scenario of the HadCM3 model projects for the period of reference a remarkable increase of the total pre- cipitations $P_{\mathrm{CUM}}$, with respect to 1990-1999 (Table 4). This derives from the underestimation of the precipitations by HadCM3 model during 1990-1999 (approximately $750 \mathrm{mmy}^{-1}$ against an observed value equal to approximately $1270 \mathrm{mmy}^{-1}$ (Groppelli and Pengo, 2005; Groppelli et al., 2010, 2011). This leads to use of a large value of $B_{\mathrm{GAO}}$ in Eq. (1) to be applied to the future precipitations supplied from the HadCM3 model (approximately $1070 \mathrm{mmy}^{-1}$ for the period 2045-2054), giving a considerable increase of $P_{\text {CUM }}$. The projected temperature increases of the HadCM3 model average approximately $1.5^{\circ} \mathrm{C}$ (Table 4$)$. The combination of the increased precipitation and future temperature leads to greater hydrological fluxes. The increase of $P_{\mathrm{CUM}}$ causes a greater amount of SWE to occur, albeit with normally anticipated ablation due to higher temperatures (Table 4, Fig. 6a). The ET flux increases (Fig. 7a), but $\phi_{\mathrm{ET}} \approx$ 0.27 in Table 4 remains approximately constant, and one observes increased discharges in all the seasons (approximately $30 \%$, Figs. 5, 9). The PCM scenarios also display an increase of $P_{\mathrm{CUM}}$, albeit smaller than the HadCM3 model, and an increase of temperatures of about $1.6^{\circ} \mathrm{C}$, approximately (Table 4).

At high altitudes, precipitation increase is shifted into a light increase of SWE, which instead decreases in the lowlands (Fig. 6b), with a bulk effect of decrease of SWE (Table 4). The ET flux increases (Fig. 7b), but remains proportionally constant ( $\phi_{\mathrm{ET}} \approx 0.28$ in Table 4$)$. As a result, in stream discharges increase on average (approximately $20 \%$, Table 4).

Model CCSM3 projects for 2045-2054 an increase of temperature of approximately $4.8^{\circ} \mathrm{C}$ on average, much greater than the other GCMs (Table 4). This is however justified by the fact that CCSM3 is of most recent implementation, and has been updated using the latest temperature data available worldwide, indicating a greater temperature rise against what initially calculated from GCMs. Moreover, the finer resolution mesh of CCSM3, with a covered area four times smaller than the two other models, possibly allows to reproduce, and project into the future, the greater observed impact of the global warming upon the European Alpine areas already reported (Beniston, 2003; Faggian and Giorgi, 2009, G. Strand, personal communication, June 2010). The scenario from model CCSM3 also displays a decrease of $P_{\mathrm{CUM}}$ (approximately $20 \%$, Table 4 ).

This scenario involves a tremendous decrease of snowpack SWE, in duration and amount ( $\mathrm{SWE}_{\mathrm{Max}}$ is three times smaller than during 1990-1999, and $\mathrm{SWE}_{\mathrm{av}}$ five times smaller, Fig. 6b, Table 4).

ET remains proportional to precipitation income $\left(\phi_{\mathrm{ET}} \approx 0.25\right.$ in Table 4$)$ but smaller than during 1990 1999 , in spite of tremendously increased temperatures. This is due to water content $\theta$ (or soil storage $S$ ), which limits transpiration from vegetation within the basin (through the $\beta$ coefficient in Eq. (12), which is null below $\theta=\theta_{w}$ ). While the reduction of soil storage $S$ observed during winter for all 
Table 4. Oglio at Sarnico. Most relevant hydrological features (yearly values). Control run 1990-1999 and scenarios, 2045-2054. Symbol = indicates a value taken as equal to value at its left. In italics are values taken from $G C M s$ and observations; normal font values are outputs from the hydrological model. Values in $\mathrm{mm}$ are weighted average upon altitude belts. Runoff and evapotranspiration coefficients are with respect to total precipitation.

\begin{tabular}{lllllllll}
\hline Variable & Description & Control/Scenario & \multicolumn{5}{c}{ Values } \\
\hline$P_{\mathrm{CUM}}[\mathrm{mm}]$ & Total precipitation & CO/LOC/HAD/PCM/CCS/CCST & 1268 & $=$ & 1810 & 1578 & 1071 & $=$ \\
$T_{\mathrm{av}}\left[{ }^{\circ} \mathrm{C}\right]$ & Temperature 2000 m a.s.l. & CO/LOC/HAD/PCM/CCS/CCST & 3.9 & 6.0 & 5.4 & 5.5 & 8.7 & 5.5 \\
$Q_{\mathrm{av}}\left[\mathrm{m}^{3} \mathrm{~s}^{-1}\right]$ & Mean in stream discharge & CO/LOC/HAD/PCM/CCS/CCST & 53.9 & 49.2 & 74.3 & 64.5 & 47.1 & 45.1 \\
$\phi_{Q}[]$. & Runoff coefficient & CO/LOC/HAD/PCM/CCS/CCST & 0.74 & 0.68 & 0.72 & 0.72 & 0.75 & 0.71 \\
$\left.\mathrm{ET}_{[\mathrm{mm}}\right]$ & Evapotranspiration & CO/LOC/HAD/PCM/CCS/CCST & 315 & 398 & 488 & 439 & 276 & 311 \\
$\phi_{\mathrm{ET}}[]$. & ET coefficient & CO/LOC/HAD/PCM/CCS/CCST & 0.25 & 0.31 & 0.27 & 0.28 & 0.25 & 0.28 \\
$S[\mathrm{~mm}]$ & Mean Soil storage & CO/LOC/HAD/PCM/CCS/CCST & 57 & 66 & 68 & 71 & 50 & 57 \\
$\mathrm{SWE}_{\max }[\mathrm{mm}]$ & Max SWE & CO/LOC/HAD/PCM/CCS/CCST & 113 & 64 & 174 & 73 & 43 & 44 \\
$\mathrm{SWE}_{\mathrm{av}}[\mathrm{mm}]$ & Mean SWE & CO/LOC/HAD/PCM/CCS/CCST & 36 & 15 & 51 & 23 & 7 & 12 \\
\hline
\end{tabular}

Table 5. Oglio at Sarnico. Relevant flow variables. Control run 1990-1999 and scenarios, 2045-2054. Bold font values are significantly $(\alpha=5 \%)$ different from control run values, as explained in Sect. 6.2.

\begin{tabular}{|c|c|c|c|c|c|c|c|c|}
\hline \multirow{2}{*}{$\begin{array}{l}\text { Variable } \\
Q_{\mathrm{av}}\left[\mathrm{m}^{3} \mathrm{~s}^{-1}\right]\end{array}$} & \multirow{2}{*}{$\begin{array}{l}\text { Description } \\
\text { Mean in stream discharge }\end{array}$} & \multirow{2}{*}{$\begin{array}{l}\text { Control/Scenario } \\
\text { CO/LOC/HAD/PCM/CCS/CCST }\end{array}$} & \multicolumn{6}{|c|}{ Values } \\
\hline & & & 54 & 55 & 80 & 69 & 47 & 46 \\
\hline$D_{\text {SWE }}{ }_{6}[$ days] & Duration snow in belt 6 & $\mathrm{CO} / \mathrm{LOC} / \mathrm{HAD} / \mathrm{PCM} / \mathrm{CCS} / \mathrm{CCST}$ & 1817 & 1138 & 1807 & 1481 & 955 & 1266 \\
\hline $\mathrm{SWE}_{\mathrm{av}, 6}[\mathrm{~mm}]$ & ean snow pack belt 6 & $\mathrm{O} / \mathrm{LOC} / \mathrm{HAD} / \mathrm{PCM} / \mathrm{CCS} / \mathrm{CCST}$ & 42 & 28 & 132 & 62 & 18 & 30 \\
\hline$Q_{\text {ind }}[1$ & dex flood & $\mathrm{CO} / \mathrm{LOC} / \mathrm{HAD} / \mathrm{PCM} / \mathrm{CCS} / \mathrm{CCST}$ & 329 & 493 & 529 & 490 & 248 & 389 \\
\hline$Q_{37}[\mathrm{n}$ & c. $10 \%$ & O/LOC/HAD/PCM/CCS/CCST & 83 & 92 & 174 & 105 & 80 & 75 \\
\hline$Q_{91}\left[\mathrm{~m}^{3} \mathrm{~s}^{-1}\right]$ & c. $25 \%$ (ordinary flood) & $\mathrm{CO} / \mathrm{LOC} / \mathrm{HAD} / \mathrm{PCM} / \mathrm{CCS} / \mathrm{CCST}$ & 60 & 53 & 92 & 58 & 53 & 47 \\
\hline$Q_{182}\left[\mathrm{~m}^{3} \mathrm{~s}^{-1}\right]$ & xc. $50 \%$ (median) & $\mathrm{CO} / \mathrm{LOC} / \mathrm{HAD} / \mathrm{PCM} / \mathrm{CCS} / \mathrm{CCST}$ & 44 & 39 & 49 & 41 & 38 & 34 \\
\hline$Q_{274}\left[\mathrm{~m}^{3} \mathrm{~s}^{-1}\right]$ & xc. $66 \%$ (ordinary low) & $\mathrm{CO} / \mathrm{LOC} / \mathrm{HAD} / \mathrm{PCM} / \mathrm{CCS} / \mathrm{CCST}$ & 33 & 28 & 32 & 29 & 27 & 24 \\
\hline$Q_{\operatorname{Max} 37}\left[\mathrm{~m}^{3} \mathrm{~s}^{-1}\right]$ & Iax av. flow 37 days & $\mathrm{CO} / \mathrm{LOC} / \mathrm{HAD} / \mathrm{PCM} / \mathrm{CCS} / \mathrm{CCST}$ & 111 & 126 & 197 & 165 & 101 & 102 \\
\hline$Q_{\operatorname{Max} 91}\left[\mathrm{~m}^{3} \mathrm{~s}^{-1}\right]$ & Iax av. flow 91 days & $\mathrm{CO} / \mathrm{LOC} / \mathrm{HAD} / \mathrm{PCM} / \mathrm{CCS} / \mathrm{CCST}$ & 82 & 87 & 140 & 113 & 72 & 72 \\
\hline$Q_{\operatorname{Max} 182}\left[\mathrm{~m}^{3} \mathrm{~s}^{-1}\right]$ & Max av. flow 182 days & $\mathrm{CO} / \mathrm{LOC} / \mathrm{HAD} / \mathrm{PCM} / \mathrm{CCS} / \mathrm{CCST}$ & 68 & 68 & 108 & 88 & 57 & 57 \\
\hline$\left[\mathrm{m}^{3} \mathrm{~s}^{-1}\right]$ & Max av. flow 274 days & $\mathrm{CO} / \mathrm{LOC} / \mathrm{HAD} / \mathrm{PCM} / \mathrm{CCS} / \mathrm{CCST}$ & 61 & 60 & 94 & 78 & 51 & 51 \\
\hline$\left[\mathrm{m}^{3} \mathrm{~s}^{-1}\right]$ & Min av. flow 37 days & $\mathrm{CO} / \mathrm{LOC} / \mathrm{HAD} / \mathrm{PCM} / \mathrm{CCS} / \mathrm{CCST}$ & 27 & 20 & 22 & 22 & 19 & 18 \\
\hline$Q_{\operatorname{Min} 91}\left[\mathrm{~m}^{3} \mathrm{~s}^{-1}\right]$ & Min av. flow 91 days & $\mathrm{CO} / \mathrm{LOC} / \mathrm{HAD} / \mathrm{PCM} / \mathrm{CCS} / \mathrm{CCST}$ & 33 & 30 & 41 & 36 & 27 & 26 \\
\hline$Q_{\operatorname{Min} 182}\left[\mathrm{~m}^{3} \mathrm{~s}^{-1}\right]$ & Min av. flow 182 days & $\mathrm{CO} / \mathrm{LOC} / \mathrm{HAD} / \mathrm{PCM} / \mathrm{CCS} / \mathrm{CCST}$ & 47 & 42 & 62 & 54 & 37 & 36 \\
\hline$Q_{\operatorname{Min} 274}\left[\mathrm{~m}^{3} \mathrm{~s}^{-1}\right]$ & Min av. flow 274 days & $\mathrm{CO} / \mathrm{LOC} / \mathrm{HAD} / \mathrm{PCM} / \mathrm{CCS} / \mathrm{CCST}$ & 51 & 50 & 79 & 64 & 43 & 42 \\
\hline
\end{tabular}

scenarios (Fig. 8a, b) has little influence upon ET in view of the low values of ETP (i.e. of low temperatures), soil storage $S$ under the CCSM3 scenario (Table 4) decreases noticeably at the onset of summer (Fig. 8b). Increased temperatures draw moisture from the soil due to increased ETP, and therefore water stress $\left(\theta<\theta_{w}\right)$ is reached quickly, making transpiration from vegetation null thenceforward.

According to Fig. 3, vegetation cover $f_{v}$ is pretty high all over the watershed, unless for the highest altitudes, so this effect reduces heavily the average ET.

To evaluate the sensitivity of the hydrological cycle to the strong temperature rise projected by the model CCSM3, another "hybrid" scenario is used, merging precipitation by CCSM3, with the more conservative scenario of tempera- tures from the model PCM (approximately $+1.6^{\circ} \mathrm{C}$ on average, similar to HadCM3). This scenario, which we call CCSM3T here, is not physically reasonable (as it is not correct to stir projections of a variable from one GCM with those of other variables coming from another GCM), but it allows to assess the potential effect of a milder temperature regime within a scenario of decreased precipitation. The main results of this scenario are also given in Table 4 and in the figures. Under the CCSM3T scenario a considerable variation (i.e. increase) of SWE (Fig. 6b), ET (Fig. 7b) and $S$ (Fig. 8b) is observed with respect to CCSM3 (see also Table 4). The results for ET and $S$ demonstrate the effect of decreased soil moisture upon evapotranspiration fluxes, as observed under the CCSM3 scenario. The average discharge given by the 

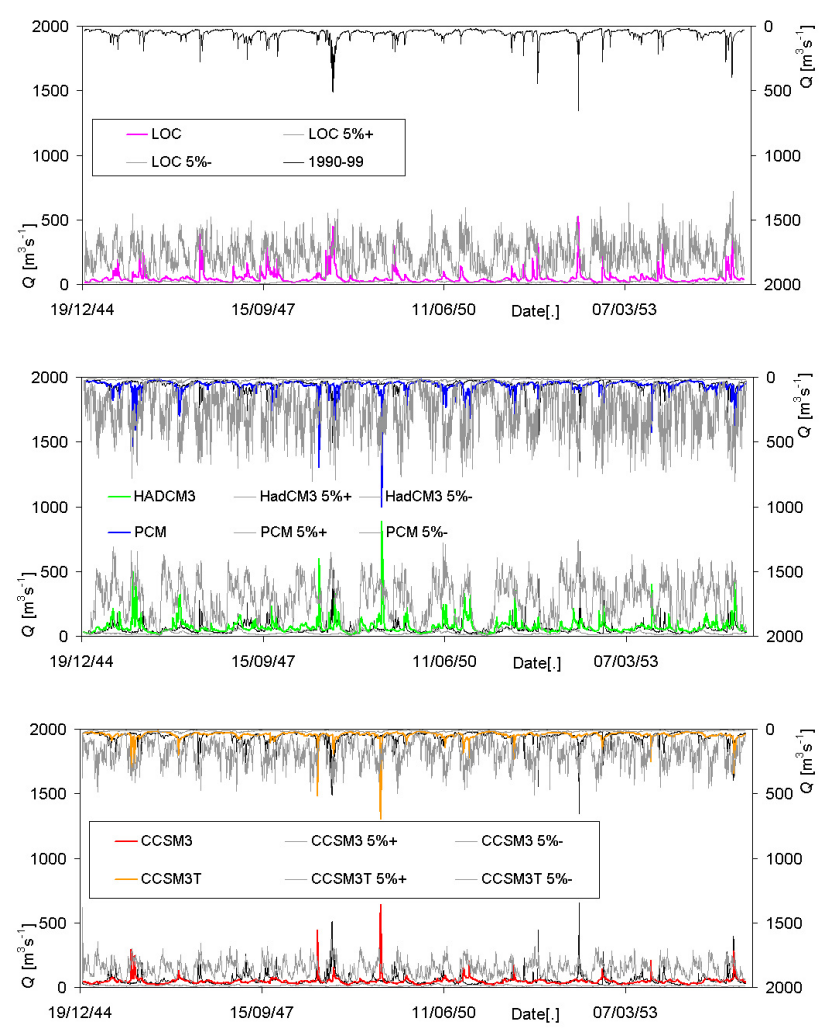

Fig. 5. Oglio at Sarnico. Scenario simulations, period 2045-2054. Daily flow discharges. Reference scenarios are reported together with confidence bounds from ensemble simulations $(\alpha=5 \%)$. Observed discharges (1990-1999) reported, black line. (a) LOC. (b) HadCM3, PCM. (c) CCSM3, CCSM3T.

CCSM3T scenario is slightly lower than that given by the CCSM3 (Table 4, Fig. 9), but yet this seems linked to decreased dampening effect of snow cover, in view of the shortened duration of seasonal snowpack (Fig. 6b).

\subsection{Uncertainty of projected scenarios}

Each GCM provides in practice one single (deterministic) realization (or trajectory) of the climate variables for the considered time window, cascading into one (as well deterministic) realization of the inflow discharge process in our watershed. However, one would like to quantify the amount of uncertainty embedded within water resources assessment, say by attaching to the projected discharges (and related flow indicators) some "error bars", possibly for a given level of confidence (e.g. $\alpha=5 \%$ ). One way of doing so is to feed the deterministic (hydrological) model an ensemble of different projected climate trajectories, all statistically equivalent to the initial, deterministic one from the GCM. This rationale is applied, for instance, in flood forecasting exercises, when different ensemble trajectories as drawn from statistical perturbation of one deterministic input are fed to a hydrological model (e.g. Lardet and Obled, 1994; Bocchiola
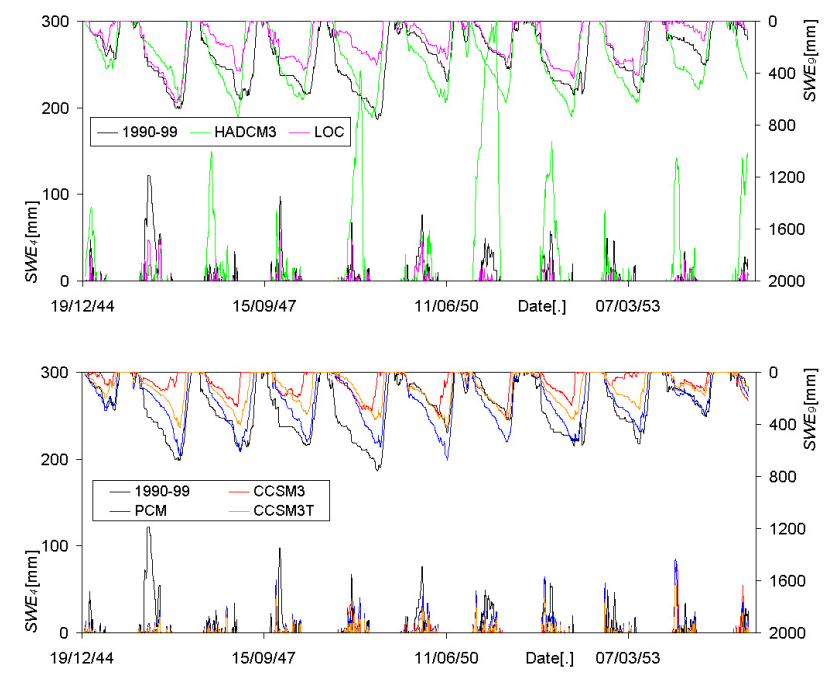

Fig. 6. Oglio at Sarnico. Scenario simulations, period 2045-2054. Snowpack SWE at belts 4 (1225 m s.l.m.) and 9 (2975 m s.l.m.). (a) LOC, HadCM3. (b) PCM, CCSM3, CCSM3T. Notice different scaling of left and right y-axis.
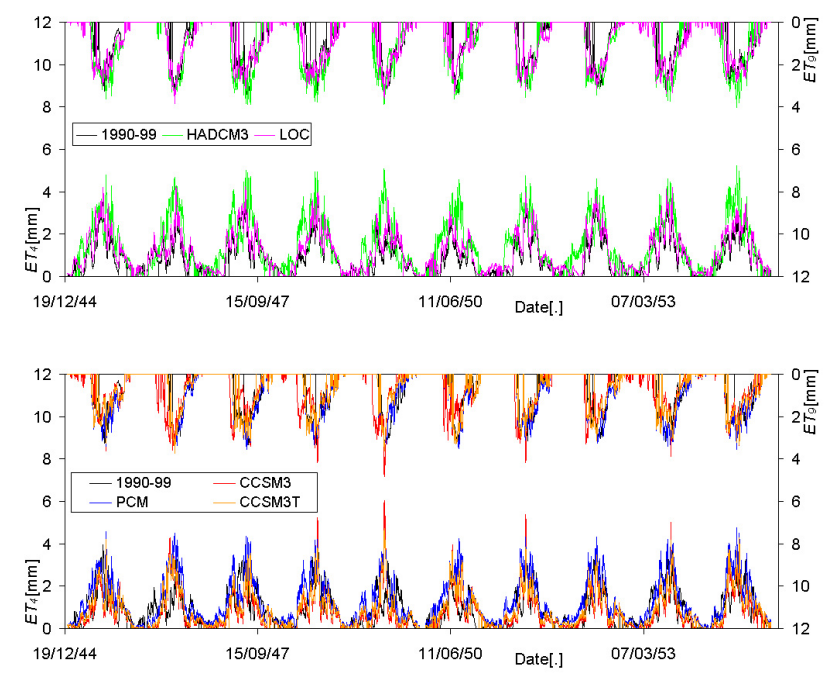

Fig. 7. Oglio at Sarnico. Scenario simulations, period 2045-2054. ET at belts 4 (1225 m s.l.m.) and 9 (2975 m s.l.m.). (a) LOC, HadCM3. (b) PCM, CCSM3, CCSM3T.

and Rosso, 2006; Mascaro et al., 2008; 2010a, b). Here, we proceeded as follows. We used the downscaled (in time) series of area averaged precitation $R_{\mathrm{GAO}}$ from each GCM as a reference simulation. Rather than downscaling several times the same GCM precipitation series, we used a Montecarlo simulation to generate an ensemble (of numerosity $s=100$ ) of possible trajectories $R_{\mathrm{GAO}, s}$, all statistically equivalent to the reference one $R_{\mathrm{GAO}}$. Rainfall simulation was carried out by a daily point site statistical precipitation model already developed elsewhere (based upon independent rectangular 

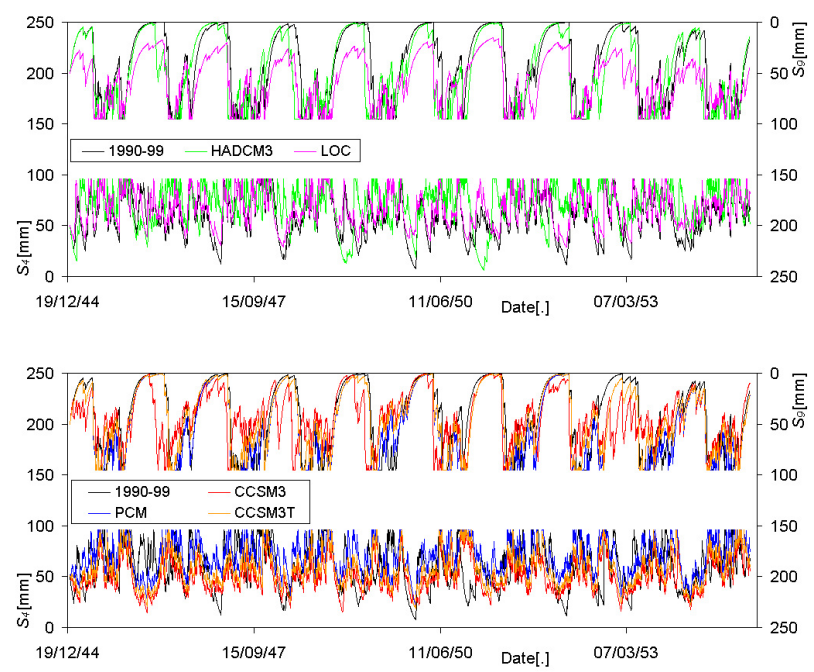

Fig. 8. Oglio at Sarnico. Scenario simulations, period 20452054. $S$ at belts 4 (1225 m s.l.m.) and 9 (2975 m s.l.m.). (a) LOC, HadCM3. (b) PCM, CCSM3, CCSM3T.

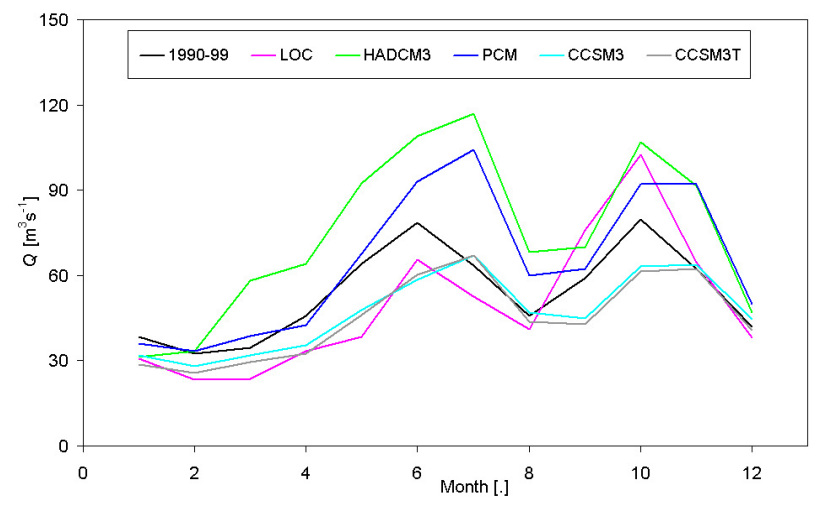

Fig. 9. Oglio at Sarnico. Scenario simulations, period 2045-2054. Average monthly discharges. CCSM3 and CCSM3 are plotted in different colors for readability.

pulses, Bocchiola et al., 2009), accounting for intermittence, i.e. for wet and dry spells, and for daily precipitation in wet days using a Lognormal distribution. The model was tuned against the $R_{\mathrm{GAO}}$ series. Then, we downscaled the so obtained $R_{G A O, s}$ series, using our stochastic space random cascade (Eq. 2-4) to obtain spatially distributed precipitation. So doing, we obtained 100 ensemble precipitation scenarios, all equivalent to the reference one used in Sect. 6.1. The correspondent daily temperature series (at the GCM reference altitude) $T_{\mathrm{GCM}, s}$ were generated according to random extraction of independent values from a normal distribution, with the known statistics drawn from the $T_{\mathrm{GCM}}$ series, and then downscaled upon the different belts according to Eq. (6). The so obtained ensemble trajectories were then fed to the hydrological model to obtain ensemble trajectories of daily

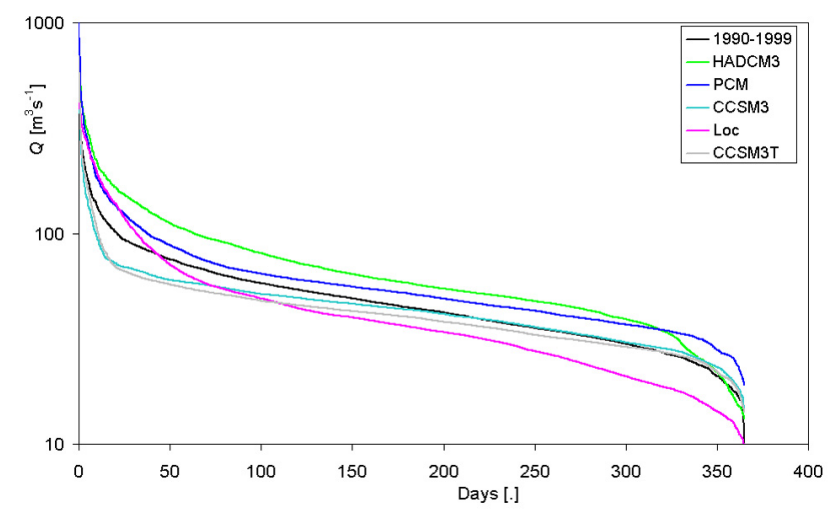

Fig. 10. Oglio at Sarnico. Scenario simulations, period 2045-2054. Flow duration curves. Logarithmic scale is used in y-axis for better readability. CCSM3 and CCSM3 have here differentare plotted in colors for readability.

discharges (together with the other variables of the model). For each scenario (GCMs + LOC) the ensemble simulations (100 trajectories of $10 \mathrm{yr}$ daily rainfall, temperature, and all the daily hydrological variables) required about 1 hour (using MATLAB ${ }^{\circledR} 7$ on a desktop PC, Windows XP®, $3 \mathrm{~Gb}$ RAM, 3.2 Ghz CPU Clock). In Fig. 5, together with the flow discharges as from the deterministic simulation, we report the upper and lower bounds $(\alpha=5 \%)$ of the daily flow discharges for each scenario, as obtained by ranking of the values given by the ensemble projections. These provide visually an idea of the expected spread (uncertainty) of the projected discharges. Notice that in few cases, the deterministic value may lay outside (below, or above) the $5 \%$ confidence range from the ensemble simulations. In Table 5 we provide for each scenario the average yearly discharge, as given by the ensembles, $Q_{\mathrm{av}, \mathrm{s}}$. Using the confidence bounds $(\alpha=5 \%)$, as obtained by ranking the values of $Q_{\mathrm{av}, s}$ for our 100 simulations, it is possible to test whether $Q_{\mathrm{av}, s}$ is significantly different from the control run value of yearly average discharge $\left(Q_{\mathrm{av}}=53.9 \mathrm{~m}^{3} \mathrm{~s}^{-1}\right.$, in Table 4). Further on, it seems interesting to test here the significance of the future amount and duration of snow cover, which is of tremendous importance as reported. For shortness, we considered here belt 6 (mean altitude, $1925 \mathrm{~m}$ a.s.1.), representative of an altitude of 2000 or so. In Table 5 we report the average (year round) value of snowpack SWE in that belt $\mathrm{SWE}_{\mathrm{av}, 6}$, together with the duration of snow cover (SWE $>0$ ) $D_{\mathrm{SWE}, 6}$, in the control run (1990-1999), and under our different scenarios. Based upon the ensemble simulations, we can provide a judgment of significance about the projected values of these variables, as compared against the control run values.

\subsection{Future hydrological flow descriptors}

In Fig. 10 we report the modified flow duration curves, hereon FDCs (e.g. Smakhtin, 2001), for the proposed 
scenarios. While FDCs do not give indication of flow seasonality, they provide visual assessment of the duration of periods (number of days) with discharge above given values, of interest for water resources management as well as for evaluation of ecological effect of flows (e.g. Clausen and Biggs, 2000; Dankers and Feyen, 2008). In Table 5 we also provide numerical comparison of some flow descriptors drawn by the FDCs, usually considered for characterization of flow regimes (e.g. Smakthin, 2001), namely the values of flow discharges equalled or exceeded for a given number of days, $d$, i.e. $Q_{d}$.

We consider $Q_{37}$, or flow exceeded for $10 \%$ of the time, $Q_{91}, 25 \%$ of the time, also known as ordinary flood, $Q_{182}$, i.e. median flow, and $Q_{274}$, also known as ordinary low flow. Also, we evaluated some flow frequency descriptors given by the yearly minima and maxima of average flows for a given duration $d$, i.e. $Q_{\text {Maxd }}$ and $Q_{\text {Mind }}$. Analysis of these variables is used to pursue statistical appraisal of low flows, e.g. for hydrological drought hazard analysis (e.g. Smakhtin, 2001). In Table 5 we report the average of the yearly values of $Q_{\text {Maxd }}$ and $Q_{\text {Mind }}$, for $d=37,91,182$, and 274 days. These values provide the spread between the greatest and least flows expected within the Oglio river for increasingly longer periods. The future projected values of these variables were calculated using the reference scenarios and the ensemble simulations. The values as drawn from the ensemble simulations are reported here, as based upon a greater sample (but the reference simulation gave equivalent results in practice). We assessed the significance of the values of the future flow descriptors, as compared against the control run values, by using the confidence bounds $(\alpha=5 \%)$ of the variables. We did the same for index flood $Q_{\text {ind }}$.

From the analysis of the FDCs in Fig. 10 and of the hydrological descriptors in Table 5, one can comment upon modified flow regimes regarding the different scenarios. Under the LOC scenario, flow discharges are lower than for the control period everywhere above 50 days or so, meaning that only during moderate to intense flood periods does the LOC scenario provide greater discharges, whereas

low flows are indeed lower. In Table 5, the projected $Q_{\mathrm{av}}$ is always (unless for LOC) significantly different from the control run value.

For LOC, $Q_{37}$ only is greater than for CO (92 vs. 83). All $Q_{\text {Min }}$, are smaller (but not significantly) for LOC than for $\mathrm{CO}$, while $Q_{\mathrm{Max}}$ are equivalent in practice. The index flood for LOC is $Q_{\text {ind }}=493 \mathrm{~m}^{3} \mathrm{~s}^{-1}$ (against $Q_{\text {ind }}=329 \mathrm{~m}^{3} \mathrm{~s}^{-1}$ for $\mathrm{CO}$ ), significantly indicating an increase of flood peaks due to rapider snow melting.

The FDC for HadCM3 scenario in Fig. 10 displays greater flows everywhere below 350 days or so (i.e. for very low flows), and the flow variables in Table 5 all display higher (and mostly significantly) values than for the CO scenario, as well as greater variability, especially for 37 and 91 days. The peak floods would increase noticeably, and one would have $Q_{\text {ind }}=529 \mathrm{~m}^{3} \mathrm{~s}^{-1}$. This is not surprising, given the in- creased amount of precipitation expected under the HadCM3 scenario.

The PCM scenario displays normally higher values than $\mathrm{CO}$, and more difference for a low duration $\left(Q_{37}\right)$. For PCM, $Q_{\text {ind }}=490 \mathrm{~m}^{3} \mathrm{~s}^{-1}$, displaying a noticeable increase also for this scenario, again due to increased $P_{\text {CUM }}$.

For CCSM3 the FDC is lower than that of CO below 200 days or so (i.e. for floods and moderate to low flows) and thereforward very close to it until 300 days or so, where it becomes slightly higher. Average discharges for different durations are always lower for CCSM3 than for $\mathrm{CO}$, and with similar spread between minimum and maximum values. Peak floods are considerably lower than for CO scenario, and $Q_{\text {ind }}=248 \mathrm{~m}^{3} \mathrm{~s}^{-1}$.

For CCSM3T scenario, the FDC is below that of CO until 320 days or so, and inching very close to it for longer duration. Average flows for all durations are lower, again with very similar relative spread. Index flood is slightly higher (but not significally different) than in $\mathrm{CO}$ scenario, $Q_{\text {ind }}=389 \mathrm{~m}^{3} \mathrm{~s}^{-1}$.

\section{Discussion and conclusions}

The use of the proposed climatic scenarios under awhat-if approach, that is the simulation of the impact of a potential climatic change as given by different sources, shows a range of possible variations of the hydrological cycle of the Oglio river, strongly snowfed, for the decade 2045-2054.

The proposed scenarios show a consistent behaviour concerning the variation of the temperatures in the next fifty years or so, that are in fact expected to increase. However, there is some disagreement upon the entity of such increase. The average yearly variation of temperatures shows a minimum of $1.5^{\circ} \mathrm{C}$ for the HadCM3 model (and $1.6^{\circ} \mathrm{C}$ for model $\mathrm{PCM}$ ), an intermediate value of $2.1^{\circ} \mathrm{C}$ as from the local observed trends in last the 4 decades, and a value of $4.8^{\circ} \mathrm{C}$ according to the CCSM3 model. The amount of future total precipitation $P_{\text {CUM }}$ is even more uncertain. While models HadCM3 and PCM (properly downscaled upon the area of the Oglio river) project increasing precipitation, in the order of $40 \%$ and $25 \%$, respectively, LOC scenario would suggest almost constant, or not significantly variable precipitation, whereas the CCSM3 scenario (also downscaled upon Oglio river) would indicate a trend of decrease of $P_{\mathrm{CUM}}$, on the order of $15 \%$. As a consequence of the proposed picture, the expected variation of the hydrological cycle can be estimated qualitatively and with a noticeable amount of uncertainty. All our analyses of the hydrological scenarios agree in showing a shortened duration, and a decreased amount of the snow pack. The late spring flows, normally linked to snowpack ablation, would therefore decrease. For the PCM and HadCM3 scenarios, the increase of liquid precipitation could fill the gap of flows of snowmelt origin, delivering the same (PCM), or even more (HadCM3) discharge in that 
period, while under the other scenarios these flows would not be available anymore.

The expected yearly freshwater supply clearly depends upon the variation of the atmospheric moisture income. Should this income remain unchanged (LOC), the study projects an important increase of ET fluxes at all altitudes (Fig. 7a), proportionally greater at the higher altitudes, where the atmospheric humidity, through the dampening of the soil reservoir, would be enough to maintain high value of ET. The moderate and low flows would therefore be substantially decreasing, and the regime of the moderate to heavy floods would instead be increased, likely due to lack of snowcover storage during heavy storms.

Where besides the temperature also the precipitation total would grow noticeably, ET would grow due to increased ETP and to soil water availability. Still, in stream flows would increase in all seasons (except for being substantially constant during winter and spring for PCM).

With a decrease of $P_{\mathrm{CUM}}$ and a high increase of temperature (scene CCSM3), the hydrological effect would be utmost critical. The ETP would increase considerably due to the increase of temperature (here of $4.8^{\circ} \mathrm{C}$ on average), but the effect of the diminished water availability would act in a limiting sense, so diminishing ET in practice, particularly during summer. This limiting effect of the diminished precipitation (and of the high temperature), would likely be the most important aspect of the CCSM3 scenario, of great interest for its possible fallout upon vegetation, and also upon water use for agricultural purposes. Given the decreased snowfall, flow rates at thaw would be diminished. Eventually, under the CCSM3 scenario, a flattening of the monthly hydrograph (Fig. 9) would occur, with progressive loss of the typical bimodal shape, due on one side to the lack of considerable ablation flows, and on the other side to the decreased rainfall during fall.

Considering a temperature rise of $1.6^{\circ} \mathrm{C}$ (CCSM3T), the results would be similar, but paradoxically enough more ET fluxes would occur due to slower withdrawal of water from the ground during spring and summer, preventing vegetation from wilting. Also, some more snowcover would be allowed.

The use of ensemble simulations as reported here helps in describing the expected amount of uncertainty, or possible spread of the projected variables. Adding a proper amount of stochastic variability to the deterministic input of the GCMs allowed us to depict confidence bounds (here, $\alpha=5 \%$ ), making the comparison against the historical values more robust. Indeed, some of the proposed scenarios project significantly different flow descriptors. This provides ground for the hypothesis that an actual modification of flow regime may occur, significant beyond the models' noises.
Use of a decadal reference period as carried out here (1990-1999 and 2045-2054) may not provide a long enough series to assess robust statistics. The proposed scenarios attempt instead to supply a range of possible situations that scientists and planners will have to expect in the future evolution of water resources within the Oglio river basins, and possibly within Alpine river basins.

A remarkable source of uncertainty lies within the determination of the future trends of precipitation in the area, which is subject of a considerable debate. Brunetti et al. (2006) studied the presence of trends of precipitation in the greater Alpine region GAR, including the case study area here, using long term observations from 192 stations. The authors highlighted four different regions, displaying somewhat variable behaviour. Particularly, the Oglio river is placed along the border between their region North-West (EOF-1 in their Fig. 4), where $P_{\mathrm{CUM}}$ is clearly increasing, and their region South-East (EOF-2 in their Fig. 4) where decreasing $P_{\text {CUM }}$ is found instead, but less evidently.

Faggian and Giorgi (2009) have studied recent projections of precipitation supplied from 20 different GCM models (including HadCM3 and CCSM3 here) for GAR until 2100. With reference to period 1961-1990, the authors report possible variations (A2 scenario) of $P_{\mathrm{CUM}}$ for the decade 2045-2054 ranging approximately between $-10 \%$ and $+10 \%$ (Fig. 11 in Faggian and Giorgi, 2009) with a variability reaching $-15 \%$ in Italy, but strongly inhomogeneous in space (e.g. Fig. 5, ibidem).

In this sense, the hydrological scenarios shown here may appear all equally likely, except possibly the HadCM3, projecting heavy precipitation. However, the tremendous mismatch between the two scales of analysis makes the comparison hardly significant.

A further source of uncertainty may dwell in fact within the downscaling method. The method we applied here, particularly the Bias ${ }_{\mathrm{GAO}}$ term in Eq. (1), is based on the hypothesis that the difference between precipitation from the GCMs and that observed on the ground remains similar in the future.

This a priori assumption is not demonstrated in actuality, and could lead to poor estimation of future precipitation. However, a downscaling method is necessary, since GCMs rarely succeed in representing the dynamics of the Alpine precipitation, heavily influenced by topography.

In the future, more studies could be devoted to assess the sensitivity to the downscaling method. The hydrological model we used considers only climate forcing as given temperature and precipitation.

An important role may be played by solar radiation, which drives energetic exchange between the atmosphere, the ground, and the snowpack. Wind regime can influence evapotranspiration and snow redistribution. Here, sublimation from snowpack was not considered due to its difficulty to evaluate. As reported, measurements of those variables are not available in the area in our knowledge. 
The A2 scenario is not the only available one. Other storylines would likely provide different results. If future climatic trends should proceed along the track observed in the last forty years, we should expect a higher seasonal snowcover line, along with less melt water resources at thaw, and smaller flows in spring.

If instead increased precipitation should show up as time goes by, a retreat of snow line should still be expected, but at times with deeper snowcover at the highest altitudes. In hydrological terms, one would observe a shift and an important increase of summer flows (from June to July, with increase flows especially for the latter), and a delay (from October to November) and increase of the fall floods. Under such scenario, it would be necessary to provide new strategies for planning and management of the expected greater amount of water, and of their effects upon floods, erosions, and hydrogeological hazard. In the hypothesis of considerably lower precipitations, we would likely face the worst scenario, with constant decrease of in stream flows, loss of the seasonality, strong decrease of snow cover and greater incidence of water stress situation. Under this scenario, management strategies would become fundamental for civil and agricultural use of water, and actions would be necessary to mitigate the hydrological, ecological, and even economical (e.g. upon snow related tourism activity) effects caused from the lack of snowcover.

In conclusion, the work proposed here, even within the broad range of uncertainty as presented, provides a contribution to the assessment of the future trends of the water resources within the Italian Alpine regions and to the depiction of possible strategies of mitigation and adaptation, posing the methodological bases of for future developments in this area.

Acknowledgements. The work carried out here was carried out within the CARIPANDA project (CAmbio climatico e RIsorsa idrica nel PArco Naturale Dell'Adamello), financed by CARIPLO Foundation of Italy through "Bando Ambiente 2006". We acknowledge ENEL Produzione Milano, the Consorzio dell'Oglio Authority and ARPA Lombardia for delivering data from their data bases. The National Center for Atmospheric Research, the Hadley Centre for Climate Prediction and the IPCC are acknowledged for making available data from the GCMs. Particularly, Gary Strand of NCAR-CCR, is gratefully acknowledged for aiding in use of CCSM3 data. A. Langousis and another anonymous reviewer are kindly acknowledged for helping to improve the paper content and readability.

Edited by: R. Deidda

Reviewed by: two anonymous referees

\section{References}

Badas, M. G., Deidda, R., and Piga, E.: Modulation of homogeneous space-time rainfall cascades to account for orographic influences, Nat. Hazards Earth Syst. Sci., 6, 427-437, doi:10.5194/nhess-6-427-2006, 2006.

Bardossy, A.: Downscaling from GCMs to Local Climate through Stochastic Linkages, J. Environ. Manag., 49, 7-17, 1997.

Barnett, T. P., Adam, J. C. and Lettenmaier, D. P.: Potential impacts of a warming climate on water availability in snow-dominated regions, Nature, 438(17), 303-309, 2005.

Barontini, S., Grossi, G., Kouwen, N., Maran, S., Scaroni, P., and Ranzi, R.: Impacts of climate change scenarios on runoff regimes in the southern Alps, Hydrol. Earth Syst. Sci. Discuss., 6, 30893141, doi:10.5194/hessd-6-3089-2009, 2009.

Bates, B. C., Charles, S. P. and Hughes, J. P.: Stochastic downscaling of numerical climate model simulations, Environ. Modell. \& Software, 13, 325-331, 1998.

Bates, B. C., Kundzewicz, Z. W., Wu, S. and Palutikof, J. P.: Climate Change and Water, Technical Paper of the Intergovernmental Panel on Climate Change, IPCC Secretariat, Geneva, 210 pp., 2008.

Bavay, M., Lehning, M., Jonas, T., and Löwe, H.: Simulations of future snow cover and discharge in Alpine headwater catchments, Hydrol. Process., 23, 95-108, 2009.

Beniston, M., Keller, F., and Goyette, S.: Snow pack in the Swiss Alps under changing climatic conditions: an empirical approach for climate impacts studies, Theor. Appl. Climatol., 74, 19-31, 2003.

Beniston, M.: Climatic change and its impacts: an overview focusing on Switzerland Springer, 286 pp., 2004.

Beniston, M., Stephenson, D. B., Christensen, O. B., Ferro, C. A. T., Frei, C., Goyette, S., Halsnaes, K., Holt, T., Jylhä, K., Koffi, B., Palutikof, J., Schöll, R., Semmler, T., and Woth, K.: Future extreme events in European climate: an exploration of regional climate model projections, Climatic Change, 81(Suppl. 1), 7195, 2007.

Bocchiola, D., De Michele, C., and Rosso, R.: Review of recent advances in index flood estimation, Hydrol. Earth Syst. Sci., 7, 283-296, doi:10.5194/hess-7-283-2003, 2003.

Bocchiola, D., De Michele, C., Pecora, S. and Rosso, R.: Sul tempo di risposta dei bacini idrografici italiani, L'ACQUA, 1, 45-55, 2004 (in Italian with abstract in English).

Bocchiola, D. and Rosso, R.: Real time flood forecasting at dams: a case study in Italy, Int. Jrn. on Hydropower and Dams, 13 (1), 92-99, 2006.

Bocchiola, D.: Use of Scale Recursive Estimation for multisensor rainfall assimilation: a case study using data from TRMM and NEXRAD, Adv. Water. Resour., 30, 2354-2372, 2007.

Bocchiola, D. and Rosso, R.: The distribution of daily Snow Water Equivalent in the Central Italian Alps, Adv. Water Resources, 30, 135-147, 2007.

Bocchiola, D. and Diolaiuti, G.: Evidence of climatic trends in the Adamello glacier of Italy, Theor. App. Climat., 100, 3-4, 351369, doi:10.1007/s00704-009-0186-x., 2010.

Bocchiola, D., Medagliani, M., and Rosso, R.: Use of a regional approach for long term simulation of snow avalanche regime: a case study in the Italian Alps, Arct. Antarct. Alp. Res., 41, 3, 285-300, 2009. 
Bocchiola, D.: Regional estimation of Snow Water Equivalent using Kriging: a preliminary study within the Italian Alps, Geografia Fisica e Dinamica Quaternaria, 33, 3-14, 2010.

Bocchiola, D., Mihalcea, C., Diolaiuti, G., Mosconi, B., Smiraglia, C., and Rosso, R.: Flow prediction in high altitude ungauged catchments: a case study in the Italian Alps (Pantano Basin, Adamello Group), Adv. Water Resour., 33(10), 12241234, 2010.

Bocchiola, D. and Groppelli, B.: Spatial estimation of Snow Water Equivalent at different dates within the Adamello Park of Italy, Cold Reg. Sci. Technol., 63(3), 97-109, 2010.

Boroneant, C., Plaut, G., Giorgi, F., and Bi X.: Extreme precipitation over the Maritime Alps and associated weather regimes simulated by a regional climate model: Present-day and future climate scenarios. Theor. Appl. Climatol., 86, 1-4 , 81-99, doi:10.1007/s00704-005-0211-7, 2006.

Brunetti, M., Maugeri, M., and Nanni, T.: Changes in total precipitation, rainy days and extreme events in Northeastern Italy, Int. J. Climatol., 21, 861-871, 2001.

Brunetti, M., Maugeri, M., Nanni, T., Auer, I., Böhm, R., and Schöner, W.: Precipitation variability and changes in the greater Alpine region over the 1800-2003 period, J. Geophys. Res., 111, D11107, doi:10.1029/2005JD006674, 2006.

Brutsaert, W.: Hydrology: an introduction, Cambridge University Press, 605 pp., 2005.

Bultot, F. Gellens, F., Spreafico, M., and Schadler, B.: Ripercussions of a $\mathrm{CO}_{2}$ doubling on the water balance: a case study in Switzerland, J. Hydrol., 137, 199-208, 1992.

Burlando, P. and Rosso, R.: Extreme storm rainfall and climatic change, Atmos. Res., 27, 1-3, 169-189, 1991.

Burlando, P. and Rosso, R.: Effects of transient climate change on basin hydrology, 1. Precipitation scenarios for the Arno River Basin, central Italy, Hydrol. Process, 16, 1151-1175, 2002a.

Burlando, P. and Rosso, R.: Effects of transient climate change on basin hydrology, 2. Impacts on runoff variability of the Arno River Basin, central Italy, Hydrol. Process, 16, 1177-1199, 2002b.

Ceres, F., Chirico, G. B., and Romano, N.: Considerazioni sulla stima della capacità idrica di campo in suoli uniformi e stratificati, Atti: IX Convegno Nazionale dell'Associazione Italiana di Ingegneria Agraria, Ischia Porto, 12-16 Settembre 2009, Memoria 3-44, 2009.

Chen, J. M., Chen, X., Ju, W. and Geng, X.: Distributed hydrological model for mapping evapotranspiration using remote sensing inputs, J. Hydrology, 305, 15-39, 2005.

Citterio, M., Diolaiuti, G., Smiraglia, C., D'agata, C., Carnielli, T., Stella, G., and Siletto, G.B.: The fluctuations of Italian glaciers during the last century: a contribution to knowledge about Alpine glacier changes, Geografiska Annaler, 89, A3, 164-182, 2007.

Clausen, B. and Biggs, B. J.: Flow variables for ecological studies in temperate streams: groupings based on covariance, J. Hydrol., 237, 184-197, 2000.

Consorzio dell' Oglio-Brescia: Progetto di rilascio del Deflusso minimo vitale nel F. Oglio sub lacuale, 16 pp., 2009.

Corbari, C., Ravazzani, G., Martinelli, J., and Mancini, M.: Elevation based correction of snow coverage retrieved from satellite images to improve model calibration, Hydrol. Earth Syst. Sci., 13, 639-649, doi:10.5194/hess-13-639-2009, 2009.

Coughlan, J. and Running, S. W.: Regional ecosystem simulation:
A general model for simulating snow accumulation and melt in mountainous terrain, Landscape Ecol. 12, 119-136, 1997.

Dankers, R. and Feyen, L.: Climate change impact on flood hazard in Europe: An assessment based on high resolution climate simulations, J. Geophys. Res., 113, D19105, doi:10.1029/2007JD009719, 2008.

Drogue, G., Pfister, L., Leviandier, T., El Idrissi, A., Ifflya, J. F., Matgen, P., Humbert, J., and Hoffmann, L.: Simulating the spatio-temporal variability of streamflow response to climate change scenarios in a mesoscale basin, J. Hydrol., 293, 255-269, 2004.

Faggian, P. and Giorgi, F.: An analysis of global model projections over Italy, with particular attention to the Italian Greater Alpine Region (GAR), Climatic Change, doi:10.1007/s10584009-9584-4, 2009.

Feyen, L. and Dankers, R.:Impact of global warming on streamflow drought in Europe, J. Geophys. Res., 114, D17116, doi:10.1029/2008JD011, 2009.

Gangopadhyay, S. and Clark, M.: Statistical downscaling using K-nearest neighbors, Water Resour. Res., 41, w02024, doi:10.1029/2004wr003444, 2005.

Groppelli, B. and Pengo, A.: Sensitività climatica dei deflussi fluviali nei corsi d'acqua alpini, Master Thesis, Politecnico di Milano, in Italian, 2005.

Groppelli, B., Bocchiola, D., and Rosso, R.: Disaggregazione spaziale delle precipitazioni nivali in scenario di cambiamento climatico per un bacino alpino, Proceeding: XXXII Convegno Nazionale di Idraulica e Costruzioni Idrauliche, Palermo, 14-17 Settembre 2010 (in Italian).

Groppelli, B., Bocchiola, D., and Rosso, R.: Precipitation downscaling using random cascades: a case study in Italy, Adv. Geosci, 8, 1-6, 2010.

Groppelli, B., Bocchiola, D., and Rosso, R.: Spatial downscaling of precipitation from GCMs for climate change projections using random cascades: a case study in Italy, Water Resour. Res., doi:10.1029/2010WR009437, in press, 2011.

Gupta, R., Venugopal, V., and Foufoula-Georgiou, E.: A methodology for merging multisensor precipitation estimates based on expectation-maximization and scale-recursive estimation, J. Geophys. Res.-Atmos., 111 (D2), D02102, doi:10.1029/2004JD005568, 2006.

Hagg, W. and Braun, L.: The influence of glacier retreat on water yield from high mountain areas: comparison of Alps and central Asia, in: Climate and Hydrology of Mountain Areas, 18, 263275, edited by: De Jong, C., Collins, D., Ranzi, R., Wiley and Sons, England, 2005.

Hagg, W., Braun, L. N., Kuhn , M., and Nesgaard, T. I.: Modelling of hydrological response to climate change in glacierized Central Asian catchments, J. Hydrol., 332, 40-53, 2007.

Houghton, J. T., Ding, Y., Griggs, D. J., Noguer, M., van der Linden, P. J., Dai, X., Maskell, K., and Johnson, C. A.: IPCC Climate Change 2001: The Scientific Basis, Contribution of Working Group I in the Third Assessment Report of Intergovernmental Panel on Climate Change, Cambridge University Press, 84 pp., 2001.

Kang, B. and Ramírez, J. A.: Response of Streamflow to Weather Variability under Climate Change in the Colorado Rockies, J. Hydrol. Eng., 12, 1, 63-72, 2007.

Lammering, B. and Dwyer, I.: Improvement of water balance 
in land surface schemes by random cascade disaggregation of rainfall, Int. J. Climatol., 20, 681-695, 2000.

Lardet, P. and Obled, C.: Real time flood forecasting using a rainfall stochastic generator, J. Hydrol., 162, 391-408, 1994.

Maragno, D., Diolaiuti, G., D’agata, C., Mihalcea, C., Bocchiola, D., Bianchi Janetti, E., Riccardi, A., and Smiraglia, C.: New evidence from Italy (Adamello Group, Lombardy) for analysing the ongoing decline of Alpine glaciers, Geografia Fisica e Dinamica Quaternaria, 32, 31-39, 2009.

Mascaro G., Deidda, R., and Vivoni, E. R.: A new verification method to ensure consistent ensemble forecasts through calibrated precipitation downscaling models, Mon. Weather Rev., 136 (9), 3374-3391, doi:10.1175/2008MWR2339.1, 2008.

Mascaro, G., Vivoni, E. R., and Deidda, R.: Physical controls on the scale-dependence of ensemble streamflow forecast dispersion, Nat. Hazards Earth Syst. Sci., 10, 1605-1615, doi:10.5194/nhess-10-1605-2010, 2010.

Mascaro, G., Vivoni, E. R., and Deidda, R.: Implications of ensemble quantitative precipitation forecast errors on distributed streamflow forecasting, J. Hydrometeorol., 11, 69-86, doi:10.1175/2009JHM1144.1, 2010b.

Menabde, M. and Sivapalan, M.: Modeling of rainfall time series and extremes using bounded random cascades and Levystable distributions, Water Resour. Res., 36, 11, 3293-3300, doi:10.1029/2000WR900197, 2000.

Nakicenovic, N. and Swart R. E.: IPCC, 2000 - Emissions Scenarios. Cambridge University Press, UK, 570 pp., 2000.

Over, T. M. and Gupta, V. K.: Statistical analysis of mesoscale rainfall: dependence of a random cascade generator on large scale forcing, J. Appl. Meteorol., 33, 1526-1542, 1994.

Over, T. M. and Gupta, V. K.: A space-time theory of mesoscale rainfall using random cascade, J. Geophys. Res., 101, 319, 1996.

Peel, M. C., Finlayson, B. L., and McMahon, T. A.: Updated world map of the Köppen-Geiger climate classification, Hydrol. Earth Syst. Sci., 11, 1633-1644, doi:10.5194/hess-11-16332007, 2007.
Ranzi, R., Grossi, G., and Bacchi, B.: Ten years of monitoring areal snow pack in the Southern Alps using NOAA-AVHRR imagery, ground measurements and hydrological data, Hydrol. Process., 13, 2079-2095, 1999.

Ranzi, R., Grossi, G., Gitti, A., and Taschner, S.: Energy and mass malance of the Mandrone Glacier (Adamello, Central Alps), Geogr. Fis. Dinam. Quat., 33, 45-60, 2010.

Rosso, R.: Nash model relation to Horton order ratios, Wat. Resour. Res., 20(7), 914-920, 1984.

Smakhtin, V. U.: Low flow hydrology: a review, J. Hydrol., 240, 147-186, 2001.

Solomon, S., Qin, D., Manning, M., Chen, Z., Marquis, M., Averyt, K. B., Tignor, M., and Miller, H. L.: IPCC Fourth Assessment Report (AR4) - Climate Change 2007: The Physical Science Basis. Contribution of Working Group I to the Fourth Assessment Report of the Intergovernmental Panel on Climate Change, 2007.

Tessier, Y., Lovejoy, S., and Schertzer, D.: Universal multifractals: theory and observations for rain and clouds, J. Appl. Meteor. doi: 10.1175/1520-0450, 1993.

Timlin, D. J., Ahuja, L. R., Pachepsky, Y., Williams, R. D., Gimenez, D., and Rawls, W.: Use of Brooks-Corey parameters to improve estimates of saturated conductivity from effective porosity, Soil Sci. Soc. Am. J., 63, 1086-1092, 1999.

Veneziano, D. and Langousis, A.: The Areal Reduction Factor: a Multifractal Analysis, Water Resour. Res., 41, W07008, doi:10.1029/2004WR003765, 2005.

Veneziano, D., Langousis, A., and Furcolo, P.: Multifractality and Rainfall Extremes: A Review, Water Resour. Res., 42, W06D15, doi:10.1029/2005WR004716, 2006.

Wang, L., Koike, T., Yang, K., and Yeh, P. J. Assessment of a distributed biosphere hydrological model against streamflow and MODIS land surface temperature in the upper Tone River Basin, J. Hydrol., 377, 21-34, 2009.

Wigmosta, M. S., Vail, L. W., and Lettenmaier, D. P.: A distributed hydrology-vegetation model for complex terrain, Water Resour. Res., 30, 1665-1679, 1994. 